Article

\title{
Distinct Peculiarities of In Planta Synthesis of Isoprenoid and Aromatic Cytokinins
}

\author{
Vladimir E. Oslovsky ${ }^{1,+}{ }^{\mathbb{D}}$, Ekaterina M. Savelieva ${ }^{2,+}{ }^{+}$Mikhail S. Drenichev $^{1}$ (D, \\ Georgy A. Romanov 2,*(D) and Sergey N. Mikhailov 1,*D \\ 1 Engelhardt Institute of Molecular Biology, Russian Academy of Sciences, Vavilov Str. 32, \\ 119991 Moscow, Russia; vladimiroslovsky@gmail.com (V.E.O.); mdrenichev@mail.ru (M.S.D.) \\ 2 Timiryazev Institute of Plant Physiology, Russian Academy of Sciences, Botanicheskaya 35, \\ 127276 Moscow, Russia; savelievaek@yandex.ru \\ * Correspondence: gromanov@yahoo.com (G.A.R.); smikh@eimb.ru (S.N.M.); \\ Tel.: +7-499-678-54-00 (G.A.R.); +7-499-135-9733 (S.N.M.) \\ + Both authors contributed equally.
}

Received: 28 November 2019; Accepted: 29 December 2019; Published: 5 January 2020

check for updates

\begin{abstract}
The biosynthesis of aromatic cytokinins in planta, unlike isoprenoid cytokinins, is still unknown. To compare the final steps of biosynthesis pathways of aromatic and isoprenoid cytokinins, we synthesized a series of nucleoside derivatives of natural cytokinins starting from acyl-protected ribofuranosyl-, 2' -deoxyribofuranosyl- and 5'-deoxyribofuranosyladenine derivatives using stereoselective alkylation with further deblocking. Their cytokinin activity was determined in two bioassays based on model plants Arabidopsis thaliana and Amaranthus caudatus. Unlike active cytokinins-bases, cytokinin nucleosides lack the hormonal activity until the ribose moiety is removed. According to our experiments, ribo-, 2'-deoxyribo- and 5'-deoxyribo-derivatives of isoprenoid cytokinin $N^{6}$-isopentenyladenine turned in planta into active cytokinins with clear hormonal activity. As for aromatic cytokinins, both 2'-deoxyribo- and 5'-deoxyribo-derivatives did not exhibit analogous activity in Arabidopsis. The 5'-deoxyribo-derivatives cannot be phosphorylated enzymatically in vivo; therefore, they cannot be "activated" by the direct LOG-mediated cleavage, largely occurring with cytokinin ribonucleotides in plant cells. The contrasting effects exerted by deoxyribonucleosides of isoprenoid (true hormonal activity) and aromatic (almost no activity) cytokinins indicate a significant difference in the biosynthesis of these compounds.
\end{abstract}

Keywords: cytokinins; biosynthesis; cytokinin nucleosides; cytokinin activity; plant hormones

\section{Introduction}

Cytokinins (CKs) are a group of phytohormones that play a crucial role in many processes of plant growth and development. One of the most important effects of CKs is the stimulation of plant cell division and growth. CKs promote the formation of shoots, control the root development, stimulate seed germination and the formation of pigments, activate the chloroplast formation, etc. [1,2]. Naturally occurring CKs are adenine derivatives with a hydrophobic substituent at the $N^{6}$ position. CKs are divided into two groups depending on the structure of the $N^{6}$ substituent: (i) aliphatic or isoprenoid, including $N^{6}$-isopentenyladenine (iP) and zeatins (Figure 1A), and (ii) aromatic, including $N^{6}$-benzyladenine (BA), topolins, and $N^{6}$-furfuryladenine (kinetin) (Figure 1B) [1,2]. 


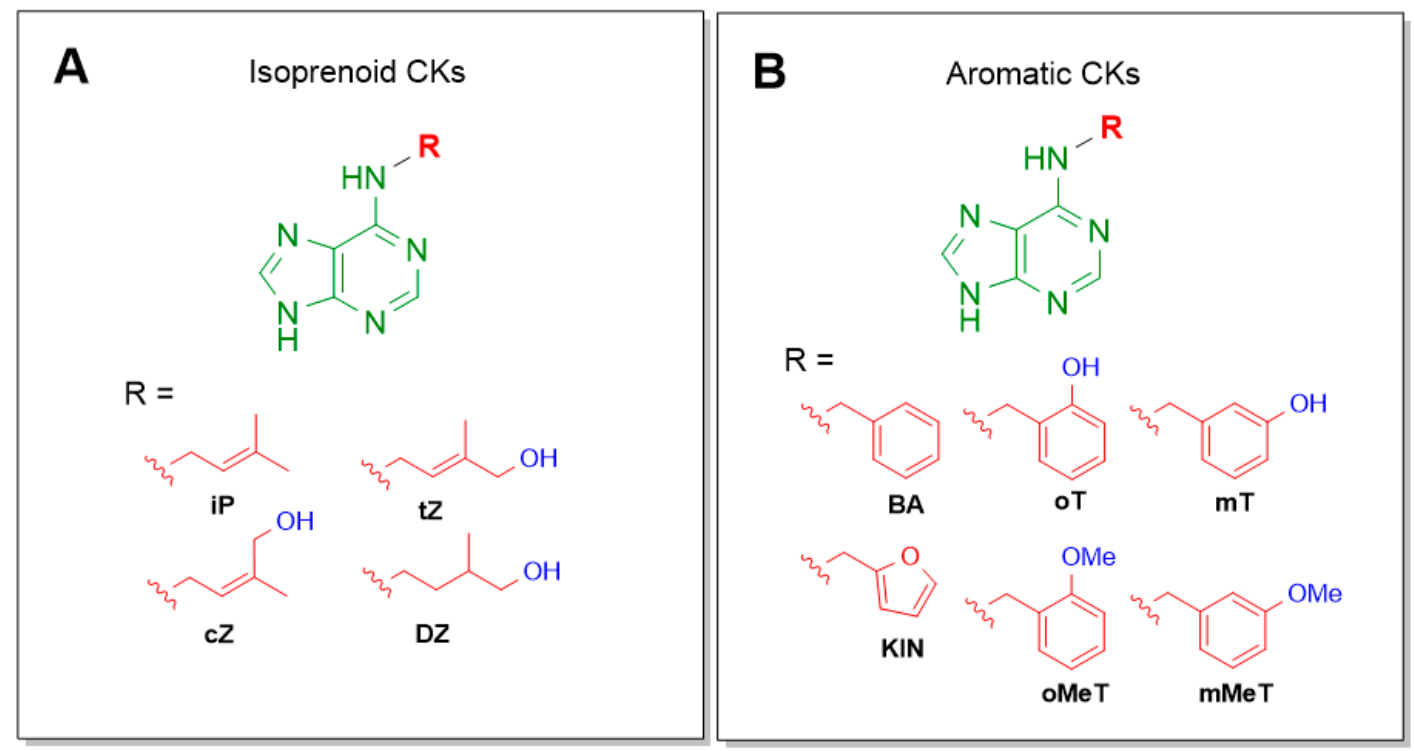

Figure 1. Names and structures of the naturally occurring cytokinins. (A) Isoprenoid (aliphatic) CKs: iP- $N^{6}$-isopentenyladenine; $c Z$-cis-zeatin ( $N^{6}$-(4-hydroxy-3-methyl-cis-2-buten-1-yl)adenine); tZ-trans-zeatin ( $N^{6}$-(4-hydroxy-3-methyl-trans-2-buten-1-yl)adenine); DZ-dihydrozeatin ( $N^{6}$-(4-hydroxy-3-methyl-2-butan-1-yl)adenine); (B) Aromatic CKs: oT-ortho-topolin ( $N^{6}$-(2-hydroxybenzyl)adenine); $\quad m \mathrm{~T}-m e t a-$ topolin $\quad$ ( $N^{6}-(3$-hydroxybenzyl)adenine); $o$ MeT-ortho-methoxytopolin $\quad\left(N^{6}-(2-m e t h o x y b e n z y l) a d e n i n e\right) ; \quad m M e T-m e t a-m e t h o x y t o p o l i n$ ( $N^{6}$-(3-methoxybenzyl)adenine); BA- $N^{6}$-benzyladenine; KIN—kinetin ( $N^{6}$-furfuryladenine).

Since the discovery of kinetin in 1955 by Miller, Skoog et al. [3], a large number of various CKs as well as corresponding nucleoside and nucleotide derivatives were synthesized or isolated from different plant sources $[4,5]$. Among these numerous molecular forms, only CKs as nucleobases possess hormonal activity, but not their nucleoside or nucleotide derivatives [6,7]. The structural diversity of CKs and CK derivatives in vivo is obviously due to complex pathways of their biosynthesis.

To date, the CK biosynthesis pathways are not completely deciphered. The biosynthesis of isoprenoid CKs, in particular iP, is most studied, while the biosynthesis pathway of aromatic CKs is practically unknown $[5,8]$. The key step of the iP biosynthesis is commonly assumed to be isopentenyl transferase-catalyzed transfer of isopentenyl moiety from dimethylallyl diphosphate (DMAPP) to the $N^{6}$ position of adenosine- $5^{\prime}$-monophosphate (AMP), adenosine- $5^{\prime}$-diphosphate (ADP) or adenosine-5'-triphosphate (ATP), with the formation of the respective $5^{\prime}$-nucleotides (iPRMP, iPRDP, iPRTP) (Figure 2). iPRDP and iPRTP are able to dephosphorylate to iPRMP. At present, two pathways of iP formation are known: (i) $5^{\prime}$-ribonucleotide phosphohydrolase (5'-nucleotidase) catalyzed conversion of iPRMP into $N^{6}$-isopentenyladenosine (iPR), followed by hydrolysis of the $\mathrm{N}$-glycosidic bond catalyzed by adenosine nucleosidase. The reverse process of ribosylation with the formation of nucleosides is catalyzed by purine nucleoside phosphorylase, and the process of reverse phosphorylation of nucleosides with the formation of nucleotides is catalyzed by adenosine kinase; (ii) iPRMP can be directly cleaved to iP by specific enzyme phosphoribohydrolase (LOG). Importantly, LOG specifically binds only the $5^{\prime}$-monophosphates of cytokinin nucleosides, but not di- or triphosphates, AMP or cytokinin ribosides. The reverse process of iPRMP formation from iP is catalyzed by adenosine phosphoribosyltransferase [9]. 


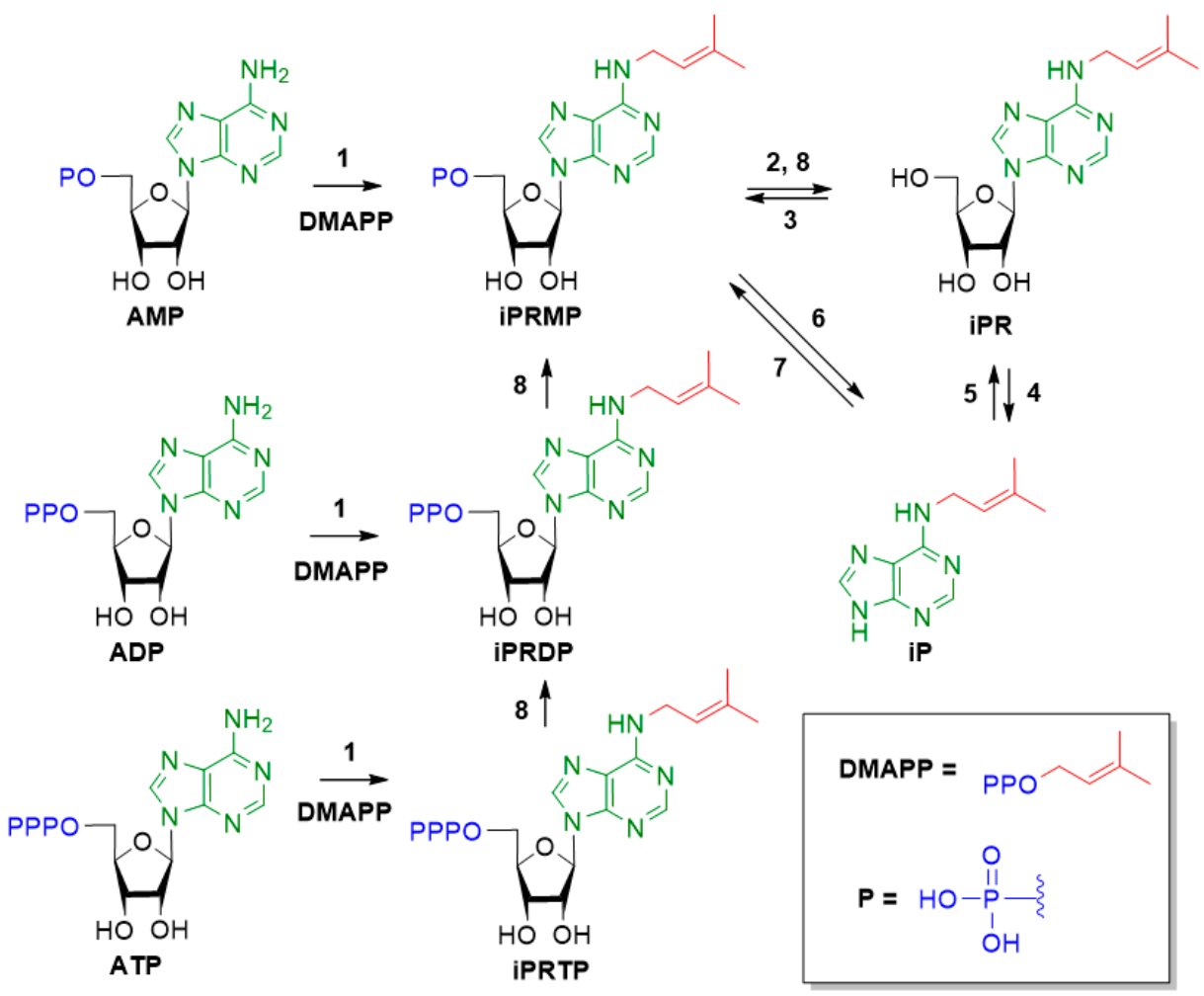

Figure 2. Scheme of the iP biosynthesis. (1) -isopentenyltransferase; (2) -5 '-ribonucleotide phosphohydrolase (5'-nucleotidase); (3)-adenosine kinase; (4)-adenosine nucleosidase; (5)—purine nucleoside phosphorylase; (6)-phosphorybohydrolase (LOG); (7)-adenosine phosphoribosyltransferase; (8)-phosphatase.

Notably, blocking the LOG-dependent pathway in complete knockout $\log$ mutants leads to severe cytokinin deficiency phenotype in Arabidopsis plants [10]. Therefore, although iPR is widely occurring in plants, it is considered to be mainly converted to iP via the second (i) LOG-dependent pathway (Figure 2, conversion 6) after reverse phosphorylation to $5^{\prime}$-monophosphate by adenosine kinase (Figure 2, conversion 3) [11].

In the present study, a new approach was proposed for the comparative analysis of the biosynthesis pathway of aromatic and isoprenoid CKs. We synthesized a series of ribo-, 2'-deoxyribo- and $5^{\prime}$-deoxyribonucleoside derivatives of natural iP, BA, KIN, and also synthetic cytokinin analog $N^{6}$-phenylethyladenine, which possesses a high hormonal activity [7]. To investigate the possibility of biochemical conversion in vivo into active CKs in comparison with corresponding ribonucleosides, a series of 2'-deoxyribonucleosides was obtained. It is well known that nucleosides are converted in vivo to $5^{\prime}$-mono-, di-, and triphosphates by cellular nucleoside kinases, and the biological activity of most nucleoside analogs is associated with this mechanism [12]. To study the role of $5^{\prime}$-phosphorylation of nucleosides in the mechanism of CK biosynthesis, a series of $5^{\prime}$-deoxyribonucleoside derivatives was obtained, which cannot be phosphorylated in vivo to form nucleotide $5^{\prime}$-monophosphates and converted into active CKs via LOG-mediated cleavage (Figure 2, conversion 6).

\section{Materials and Methods}

\subsection{Synthesis}

\subsubsection{General}

The reagents and solvents were reagent grade (Sigma Aldrich, St. Louis, MO, USA; Merck, Darmstadt, Germany; Alfa Aesar, Haverhill, MA, USA). Column chromatography was performed on 
silica gel (Kieselgel 60 Merck, 0.063-0.200 mm). Thin-layer chromatography (TLC) was performed on silica-coated aluminum plates with fluorescent indicator (Merck silica gel 60F254, Darmstadt, Germany or Alugram SIL G/UV254 Macherey-Nagel, Düren, Germany with UV visualization.

${ }^{1} \mathrm{H}$ and ${ }^{13} \mathrm{C}$ (with complete proton decoupling) NMR spectra were recorded on Bruker AMX $400 \mathrm{NMR}$ instrument at $303 \mathrm{~K} .{ }^{1} \mathrm{H}-\mathrm{NMR}$ spectra were recorded at $400 \mathrm{MHz}$ and ${ }^{13} \mathrm{C}-\mathrm{NMR}$ spectra at $100 \mathrm{MHz}$. Chemical shifts in ppm were measured relative to the residual solvent signals as internal standards $\left(\mathrm{CDCl}_{3},{ }^{1} \mathrm{H}: 7.26 \mathrm{ppm},{ }^{13} \mathrm{C}: 77.1 \mathrm{ppm}\right.$; DMSO-d $\left.\mathrm{d}_{6},{ }^{1} \mathrm{H}: 2.50 \mathrm{ppm},{ }^{13} \mathrm{C}: 39.5 \mathrm{ppm}\right)$. Spin-spin coupling constants $(J)$ are given in Hz. Hydroxyl protons in ${ }^{1} \mathrm{H}-\mathrm{NMR}$ were assigned by deuterium exchange on upon addition of $\mathrm{D}_{2} \mathrm{O}$ into DMSO- $d_{6}$ solutions of nucleosides, which led to disappearance of hydroxyl signals and simplification of ${ }^{1} \mathrm{H}-\mathrm{NMR}$ spectra.

High-resolution mass spectra (HRMS) were registered on a Bruker Daltonics micrOTOF-Q II instrument (Bruker Daltonics, Billerica, MA, USA) using electrospray ionization (ESI). Samples were injected into the mass spectrometer chamber from the Agilent 1260 HPLC system (Santa Clara, CA, USA) equipped with an Agilent Poroshell 120 EC-C18 $(3.0 \times 50 \mathrm{~mm} ; 2.7 \mu \mathrm{m})$ column (Santa Clara, CA, USA); flow rate $400 \mu \mathrm{L} / \mathrm{min}$; samples were injected from the acetonitrile-water (1:1) solution and the column was eluted with a gradient of concentrations of acetonitrile (A) in water (B) in the following parameters: $0-15 \%$ A for $6.0 \mathrm{~min}, 15 \%-85 \%$ A for $1.5 \mathrm{~min}, 85 \%-0 \%$ A for $0.1 \mathrm{~min}, 0 \%$ A for $2.4 \mathrm{~min}$. Retention times were as follows: $4-3.9 \mathrm{~min}$; $5-3.9 \mathrm{~min} ; 6-4.5 \mathrm{~min} ; 7-3.7 \mathrm{~min}$; $8-4.1 \mathrm{~min}$; 9-4.1 $\mathrm{min} ; 10-4.2 \mathrm{~min} ; 11-3.8 \mathrm{~min} ; 12-4.4 \mathrm{~min} ; 13-4.3 \mathrm{~min}$; $14-4.5 \mathrm{~min} ; 15-4.0 \mathrm{~min}$.

Melting points were measured with Electrothermal Melting Point Apparatus IA6301 (Camlab Ltd., Cambridge, UK) and are uncorrected.

The following nucleosides were prepared according to the methods reported earlier: $N^{6}$-benzyladenosine (4), $N^{6}$-isopentenyladenosine (5), $N^{6}$-furfuryladenosine (7) [13], $N^{6}-(2-$ phenylethyl)-adenosine (6), $N^{6}$-benzyl-2'-deoxyadenosine (8), $N^{6}$-(2-phenylethyl)-2' -deoxyadenosine (10), $N^{6}$-benzyl-5' -deoxyadenosine (12), $N^{6}$-isopentenyl-5'-deoxyadenosine (13), $N^{6}$-(2-phenylethyl)-5' -deoxyadenosine (14) [14].

NMR and HPLC-HRMS data are presented in full in Supplementary Information.

\subsubsection{Typical Procedure for Preparation of Nucleosides by Alkylation with Alkyl Halides}

A mixture of $N^{6}$-acetyl-2 $2^{\prime}, 3^{\prime}, 5^{\prime}$-tri-O-acetyladenosine (1) or $N^{6}$-acetyl- $3^{\prime}, 5^{\prime}$-di-O-acetyl-2 ${ }^{\prime}$ -deoxyadenosine (2) or $\mathrm{N}^{6}$-acetyl-2', $3^{\prime}$-di-O-acetyl-5'-deoxyadenosine (3) (0.5 mmol), 1,8-Diazabicyclo [5.4.0]undec-7-ene (DBU) $(1 \mathrm{mmol})$, and corresponding bromide $(1 \mathrm{mmol})$ in dry acetonitrile $(5 \mathrm{~mL})$ was kept at ambient temperature for $24 \mathrm{~h}$. The reaction was monitored by TLC (silica gel, $\mathrm{CH}_{2} \mathrm{Cl}_{2}-\mathrm{EtOH}$, 97:3). After $24 \mathrm{~h}$ the reaction mixture was concentrated in vacuo to dryness. The residue was diluted with ethyl acetate $(20 \mathrm{~mL})$ and washed successively with brine $(2 \times 20 \mathrm{~mL}), 10 \%$ aqueous sodium bicarbonate $(20 \mathrm{~mL})$ and water $(2 \times 20 \mathrm{~mL})$. The organic layer was separated, dried over anhydrous sodium sulfate, filtered, and concentrated in vacuo. The residue was purified by column chromatography on silica gel. The column was washed with methylene chloride, the product was eluted with $\mathrm{CH}_{2} \mathrm{Cl}_{2}-\mathrm{EtOH}$, 98:2. Purified acetyl-protected compound was dissolved in $4 \mathrm{M} \mathrm{n}-\mathrm{PrNH}_{2}$ in $\mathrm{MeOH}$ solution ( $50 \mathrm{mmol}$ ) and was left for $24 \mathrm{~h}$, after which the mixture was concentrated in vacuo and the residue was purified by column chromatography on silica gel. The column was washed with $\mathrm{CH}_{2} \mathrm{Cl}_{2}$ - $\mathrm{EtOH}, 95: 5$ and the product was eluted with $\mathrm{CH}_{2} \mathrm{Cl}_{2}$ - $\mathrm{EtOH}, 90: 10$. The resulting product was dried for $24 \mathrm{~h}$ in a vacuum desiccator over phosphorous pentaoxide $\left(\mathrm{P}_{2} \mathrm{O}_{5}\right)$.

$N^{6}$-benzyladenosine (4). Yield for two steps was $72 \%$ as a powder. $\mathrm{R}_{\mathrm{f}}=0.32\left(\mathrm{CHCl}_{3}\right.$-EtOH, 9:1 v/v). m.p. 164-165 ${ }^{\circ} \mathrm{C} .{ }^{1} \mathrm{H}-\mathrm{NMR}\left(400 \mathrm{MHz}, \mathrm{DMSO}-d_{6}\right): \delta=8.40 \mathrm{br} \mathrm{s}\left(1 \mathrm{H}, \mathrm{N}^{6} \mathrm{H}\right), 8.37 \mathrm{~s}(1 \mathrm{H}, \mathrm{H}-8), 8.20 \mathrm{br} \mathrm{s}(1 \mathrm{H}, \mathrm{H}-2)$, $7.37-7.17 \mathrm{~m}(5 \mathrm{H}, \mathrm{Ph}), 5.89 \mathrm{~d}\left(1 \mathrm{H}, J_{1^{\prime} 2^{\prime}}=6.1 \mathrm{~Hz}, \mathrm{H}-1^{\prime}\right), 5.41 \mathrm{~d}\left(1 \mathrm{H}, J_{\mathrm{OH}, 2^{\prime}}=6.2 \mathrm{~Hz}, 2-\mathrm{OH}^{\prime}\right), 5.34 \mathrm{dd}\left(1 \mathrm{H}, J_{\mathrm{OH}, 5^{\prime} \mathrm{b}}\right.$ $\left.=7.1 \mathrm{~Hz}, J_{\mathrm{OH}, 5^{\prime} \mathrm{a}}=4.6 \mathrm{~Hz}, 5-\mathrm{OH}^{\prime}\right), 5.15 \mathrm{~d}\left(1 \mathrm{H}, J_{\mathrm{OH}, 3^{\prime}}=4.7 \mathrm{~Hz}, 3-\mathrm{OH}^{\prime}\right), 4.72 \mathrm{br} \mathrm{s}\left(2 \mathrm{H}, N^{6} \mathrm{HC}_{2}\right), 4.61 \mathrm{ddd}$ $\left(1 \mathrm{H}, J_{2^{\prime} 3^{\prime}}=5.1 \mathrm{~Hz}, J_{2^{\prime} 1^{\prime}}=6.1 \mathrm{~Hz}, J_{2^{\prime} \mathrm{OH}}=6.2 \mathrm{~Hz}, \mathrm{H}-2^{\prime}\right), 4.15 \mathrm{ddd}\left(1 \mathrm{H}, J_{3^{\prime} 4^{\prime}}=2.8 \mathrm{~Hz}, J_{3^{\prime} 2^{\prime}}=5.1 \mathrm{~Hz}, J_{3^{\prime} \mathrm{OH}}=\right.$ $\left.4.7 \mathrm{~Hz}, \mathrm{H}-3^{\prime}\right), 3.97 \mathrm{ddd}\left(1 \mathrm{H}, J_{4^{\prime} 5^{\prime} \mathrm{b}}=3.8 \mathrm{~Hz}, J_{4^{\prime} 5^{\prime} \mathrm{a}}=3.3 \mathrm{~Hz}, J_{4^{\prime} 3^{\prime}}=2.8 \mathrm{~Hz}, \mathrm{H}-4^{\prime}\right), 3.67 \mathrm{ddd}\left(1 \mathrm{H}, J_{5^{\prime} \mathrm{a} 5^{\prime} \mathrm{b}}=-12.1\right.$ $\left.\mathrm{Hz}, J_{5^{\prime} \mathrm{a} 4^{\prime}}=3.3 \mathrm{~Hz}, J_{5^{\prime} \mathrm{a}, \mathrm{OH}}=4.6 \mathrm{~Hz}, \mathrm{H}-5^{\prime} \mathrm{a}\right), 3.56 \mathrm{ddd}\left(1 \mathrm{H}, J_{5^{\prime} \mathrm{b} 5^{\prime} \mathrm{a}}=-12.1 \mathrm{~Hz}, J_{5^{\prime} \mathrm{b} 4^{\prime}}=3.8 \mathrm{~Hz}, J_{5^{\prime} \mathrm{b}, \mathrm{OH}}=7.1 \mathrm{~Hz}\right.$, H-5'b). ${ }^{13}$ C NMR (100 MHz, DMSO-d6): 154.62 (C-6), 152.39 (C-2), 148.48 (C-4), 139.96 (C-8), 128.26 (Ph), 
127.16 (Ph), $126.68(\mathrm{Ph}), 119.78$ (C-5), $88.05\left(\mathrm{C}-1^{\prime}\right), 85.96\left(\mathrm{C}-4^{\prime}\right), 73.58\left(\mathrm{C}-2^{\prime}\right), 70.70\left(\mathrm{C}-3^{\prime}\right), 61.72\left(\mathrm{C}-5^{\prime}\right), 42.99$ $\left(\mathrm{NHCH}_{2}\right)$. HRMS: $m / z[\mathrm{M}+\mathrm{H}]^{+}$calculated $\mathrm{C}_{17} \mathrm{H}_{20} \mathrm{~N}_{5} \mathrm{O}_{4}{ }^{+} 358.1510$, found 358.1510 .

$N^{6}$-isopentenyladenosine (5). Yield for two steps was $91 \%$ as a powder. $\mathrm{R}_{f}=0.45\left(\mathrm{CH}_{2} \mathrm{Cl}_{2}-\mathrm{EtOH}\right.$, $4: 1$ v/v). m.p. ${ }^{144-146}{ }^{\circ} \mathrm{C} .{ }^{1} \mathrm{H}-\mathrm{NMR}\left(400 \mathrm{MHz}, \mathrm{DMSO}-d_{6}\right): \delta=8.31 \mathrm{~s}(1 \mathrm{H}, \mathrm{H}-8), 8.19 \mathrm{br} \mathrm{s}(1 \mathrm{H}$, $\mathrm{H}-2), 7.82$ br s $\left(1 \mathrm{H}, N^{6} \mathrm{H}\right), 5.87 \mathrm{~d}\left(1 \mathrm{H}, J_{1^{\prime} 2^{\prime}}=6.0 \mathrm{~Hz}, \mathrm{H}-1^{\prime}\right), 5.40 \mathrm{~d}\left(1 \mathrm{H}, J_{\mathrm{OH}, 2^{\prime}}=6.2 \mathrm{~Hz}, 2-\mathrm{OH}^{\prime}\right)$, $5.39 \mathrm{dd}\left(1 \mathrm{H}, J_{\mathrm{OH}, 5^{\prime} \mathrm{b}}=7.9 \mathrm{~Hz}, J_{\mathrm{OH}, 5^{\prime} \mathrm{a}}=4.6 \mathrm{~Hz}, 5-\mathrm{OH}^{\prime}\right), 5.33-5.27 \mathrm{~m}\left(1 \mathrm{H}, \mathrm{CC} \underline{\mathrm{H}}=\mathrm{CMe}_{2}\right), 5.15 \mathrm{~d}(1 \mathrm{H}$, $\left.J_{\mathrm{OH}, 3^{\prime}}=4.8 \mathrm{~Hz}, 3-\mathrm{OH}^{\prime}\right), 4.60 \mathrm{ddd}\left(1 \mathrm{H}, J_{2^{\prime} 3^{\prime}}=5.3 \mathrm{~Hz}, J_{2^{\prime} 1^{\prime}}=6.0 \mathrm{~Hz}, J_{2^{\prime} \mathrm{OH}}=6.2 \mathrm{~Hz}, \mathrm{H}-2^{\prime}\right), 4.14 \mathrm{ddd}(1 \mathrm{H}$, $\left.J_{3^{\prime} 4^{\prime}}=2.8 \mathrm{~Hz}, J_{3^{\prime} 2^{\prime}}=5.3 \mathrm{~Hz}, J_{3^{\prime} \mathrm{OH}}=4.8 \mathrm{~Hz}, \mathrm{H}-3^{\prime}\right), 4.08 \mathrm{br} \mathrm{s}\left(2 \mathrm{H}, N^{6} \mathrm{HCH}_{2}\right), 3.96 \mathrm{ddd}\left(1 \mathrm{H}, J_{4^{\prime} 5^{\prime} \mathrm{b}}=3.0 \mathrm{~Hz}\right.$, $\left.J_{4^{\prime} 5^{\prime} \mathrm{a}}=3.6 \mathrm{~Hz}, J_{4^{\prime} 3^{\prime}}=2.8 \mathrm{~Hz}, \mathrm{H}-4^{\prime}\right), 3.67 \mathrm{ddd}\left(1 \mathrm{H}, J_{5^{\prime} \mathrm{a} 5^{\prime} \mathrm{b}}=-12.1 \mathrm{~Hz}, J_{5^{\prime} \mathrm{a} 4^{\prime}}=3.6 \mathrm{~Hz}, J_{5^{\prime} \mathrm{a}, \mathrm{OH}}=4.6 \mathrm{~Hz}\right.$, $\left.\mathrm{H}-5^{\prime} \mathrm{a}\right), 3.55 \mathrm{ddd}\left(1 \mathrm{H}, J_{5^{\prime} \mathrm{b} 5^{\prime} \mathrm{a}}=-12.1 \mathrm{~Hz}, J_{5^{\prime} \mathrm{b} 4^{\prime}}=3.0 \mathrm{~Hz}, J_{5^{\prime} \mathrm{b}, \mathrm{OH}}=7.9 \mathrm{~Hz}, \mathrm{H}-5^{\prime} \mathrm{b}\right) .{ }^{13} \mathrm{C} \mathrm{NMR}(100 \mathrm{MHz}$, DMSO-d6): 154.93 (C-6), 153.14 (C-2), 148.63 (C-4), 140.49 (C-8), 135.41 (=CMe $), 121.73$ (CH=), 120.14 (C-5), $88.79\left(\mathrm{C}-1^{\prime}\right), 86.57\left(\mathrm{C}-4^{\prime}\right), 74.22\left(\mathrm{C}-2^{\prime}\right), 71.20\left(\mathrm{C}-3^{\prime}\right), 62.22\left(\mathrm{C}-5^{\prime}\right), 38.57\left(\mathrm{NHCH}_{2}\right), 26.02(\mathrm{Me}), 18.49$ (Me). HRMS: $m / z[\mathrm{M}+\mathrm{H}]^{+}$calculated $\mathrm{C}_{15} \mathrm{H}_{22} \mathrm{~N}_{5} \mathrm{O}_{4}{ }^{+} 336.1666$, found 336.1666 .

$N^{6}$-benzyl-2'-deoxyadenosine(8). Yield for two steps was $55 \%$ as a foam. $\mathrm{R}_{f} 0.08\left(\mathrm{CH}_{2} \mathrm{Cl}_{2}-\mathrm{EtOH}, 97: 3\right) .{ }^{1} \mathrm{H} \mathrm{NMR}$ (400 MHz, DMSO- $d_{6}$ ): $\delta=8.41$ (br s, $\left.1 \mathrm{H}, N^{6} \mathrm{H}\right), 8.35$ (s, 1H, H2), 8.19 (s, 1H, H8), 7.37-7.16 (m, 5H, Ph), 6.35 $\left(\mathrm{dd}, 1 \mathrm{H}, J_{1^{\prime}, 2^{\prime} \mathrm{b}}=5.9 \mathrm{~Hz}, J_{1^{\prime}, 2^{\prime} \mathrm{a}}=7.8 \mathrm{~Hz}, \mathrm{H} 1^{\prime}\right), 5.30\left(\mathrm{~d}, 1 \mathrm{H}, J_{\mathrm{OH}, 3^{\prime}}=3.9 \mathrm{~Hz}, 3^{\prime} \mathrm{OH}\right), 5.20\left(\mathrm{dd}, 1 \mathrm{H}, J_{\mathrm{OH}, 5^{\prime} \mathrm{a}}=5.2\right.$ $\left.\mathrm{Hz}, J_{\mathrm{OH}, 5^{\prime} \mathrm{b}}=6.4 \mathrm{~Hz}, 5^{\prime} \mathrm{OH}\right), 4.70\left(\mathrm{br} \mathrm{s}, 2 \mathrm{H}, \mathrm{NHC}_{2}\right), 4.40\left(\mathrm{dddd}, 1 \mathrm{H}, J_{3^{\prime} 4^{\prime}}=2.5 \mathrm{~Hz}, J_{3^{\prime} 2^{\prime} \mathrm{a}}=5.7 \mathrm{~Hz}, J_{3^{\prime} 2^{\prime} \mathrm{b}}=2.3\right.$ $\left.\mathrm{Hz}, J_{3^{\prime} \mathrm{OH}}=3.9 \mathrm{~Hz}, \mathrm{H} 3^{\prime}\right), 3.88\left(\mathrm{ddd}, 1 \mathrm{H}, J_{4^{\prime}, 3^{\prime}}=2.3 \mathrm{~Hz}, J_{4^{\prime}, 5^{\prime} \mathrm{a}}=3.9 \mathrm{~Hz}, J_{4^{\prime}, 5^{\prime} \mathrm{b}}=6.2 \mathrm{~Hz}, \mathrm{H} 4^{\prime}\right), 3.62(\mathrm{ddd}, 1 \mathrm{H}$, $\left.J_{5^{\prime} \mathrm{a}, 4^{\prime}}=3.9 \mathrm{~Hz}, J_{5^{\prime} \mathrm{a}, 5^{\prime} \mathrm{b}}=-12.0 \mathrm{~Hz}, J_{5^{\prime} \mathrm{a}, \mathrm{OH}}=5.2 \mathrm{~Hz}, \mathrm{H} 5^{\prime} \mathrm{a}\right), 3.51\left(\mathrm{ddd}, 1 \mathrm{H}, J_{5^{\prime} \mathrm{b}, 4^{\prime}}=6.2 \mathrm{~Hz}, J_{5^{\prime} \mathrm{b}, 5^{\prime} \mathrm{a}}=-12.0 \mathrm{~Hz}\right.$, $\left.J_{5^{\prime} \mathrm{b}, \mathrm{OH}}=6.4 \mathrm{~Hz}, \mathrm{H} 5^{\prime} \mathrm{b}\right), 2.74\left(\mathrm{ddd}, 1 \mathrm{H}, J_{2^{\prime} \mathrm{a}, 1^{\prime}}=7.8 \mathrm{~Hz}, J_{2^{\prime} \mathrm{a}, 3^{\prime}}=5.7 \mathrm{~Hz}, J_{2^{\prime} \mathrm{a}, 2^{\prime} \mathrm{b}}=-13.1 \mathrm{~Hz}, \mathrm{H} 2^{\prime} \mathrm{a}\right), 2.25(\mathrm{ddd}$, $\left.1 \mathrm{H}, J_{2^{\prime} \mathrm{b}, 1^{\prime}}=5.8 \mathrm{~Hz}, J_{2^{\prime} \mathrm{b}, 3^{\prime}}=2.3 \mathrm{~Hz}, J_{2^{\prime} \mathrm{b}, 2^{\prime} \mathrm{a}}=-13.1 \mathrm{~Hz}, \mathrm{H} 2^{\prime} \mathrm{b}\right) .{ }^{13} \mathrm{C}$ NMR $\left(400 \mathrm{MHz}, \mathrm{DMSO}-d_{6}\right): \delta=154.90$ (C6), 152.86 (C2), 148.61 (C4), $140.10(\mathrm{C} 8), 128.82$ (Ph), 127.58 (Ph), 127.32 (Ph), 119.55 (C5), 88.28 (C1'), 84.62 $\left(\mathrm{C} 4^{\prime}\right), 71.34\left(\mathrm{C}^{\prime}\right), 62.20\left(\mathrm{C}^{\prime}\right), 43.38\left(\mathrm{NHCH}_{2}\right), 39.49\left(\mathrm{C}^{\prime}\right.$ overlapping with DMSO). HRMS: $\mathrm{m} / z$ [M + H] ${ }^{+}$ calculated $\mathrm{C}_{17} \mathrm{H}_{20} \mathrm{~N}_{5} \mathrm{O}_{3}{ }^{+} 342.1561$, found 342.1562; $/ z$ [M-deoxyribosyl] ${ }^{+}$calculated $\mathrm{C}_{12} \mathrm{H}_{12} \mathrm{~N}_{5}{ }^{+}$226.1087, found 226.1083 .

$N^{6}$-isopentenyl-2'-deoxyadenosine(9). Yield for two steps was $43 \%$ as a foam. $\mathrm{R}_{f} 0.33\left(\mathrm{CH}_{2} \mathrm{Cl}_{2}\right.$-EtOH, 95:5). ${ }^{1} \mathrm{H}$ NMR $\left(400 \mathrm{MHz}\right.$, DMSO- $\left.d_{6}\right): \delta=8.30 \mathrm{~s}(1 \mathrm{H}, \mathrm{H}-2), 8.18 \mathrm{br} \mathrm{s}(1 \mathrm{H}, \mathrm{H}-8), 7.79 \mathrm{br} \mathrm{s}\left(1 \mathrm{H}, N^{6} \mathrm{H}\right), 6.34 \mathrm{dd}\left(1 \mathrm{H}, J_{1^{\prime} 2^{\prime} \mathrm{b}}\right.$ $\left.=6.0 \mathrm{~Hz}, J_{1^{\prime} 2^{\prime} \mathrm{a}}=7.5 \mathrm{~Hz}, \mathrm{H}-1^{\prime}\right), 5.30 \mathrm{dd}\left(1 \mathrm{H}, J_{\mathrm{CHCH} 3}=1.2 \mathrm{~Hz}, J_{\mathrm{CHCH} 2}=6.5 \mathrm{~Hz}, \mathrm{C} \underline{\mathrm{H}}=\mathrm{CMe}_{2}\right), 5.27 \mathrm{~d}(1 \mathrm{H}$, $\left.J_{\mathrm{OH}, 3^{\prime}}=4.0 \mathrm{~Hz}, 3-\mathrm{OH}^{\prime}\right), 5.18 \mathrm{dd}\left(1 \mathrm{H}, J_{\mathrm{OH}, 5^{\prime} \mathrm{b}}=6.4 \mathrm{~Hz}, J_{\mathrm{OH}, 5^{\prime} \mathrm{a}}=4.8 \mathrm{~Hz}, 5-\mathrm{OH}^{\prime}\right), 4.40$ dddd $\left(1 \mathrm{H}, J_{3^{\prime} 4^{\prime}}=2.7\right.$ $\left.\mathrm{Hz}, J_{3^{\prime} 2^{\prime} \mathrm{a}}=5.9 \mathrm{~Hz}, J_{3^{\prime} 2^{\prime} \mathrm{b}}=2.9 \mathrm{~Hz}, J_{3^{\prime} \mathrm{OH}}=4.0 \mathrm{~Hz}, \mathrm{H}-3^{\prime}\right), 4.07 \mathrm{br} \mathrm{s}\left(2 \mathrm{H}, N^{6} \mathrm{HCH}_{2}\right), 3.88$ ddd $\left(1 \mathrm{H}, J_{4^{\prime} 5^{\prime} \mathrm{b}}=4.2\right.$ $\left.\mathrm{Hz}, J_{4^{\prime} 5^{\prime} \mathrm{a}}=4.4 \mathrm{~Hz}, J_{4^{\prime} 3^{\prime}}=2.7 \mathrm{~Hz}, \mathrm{H}-4^{\prime}\right), 3.62 \mathrm{ddd}\left(1 \mathrm{H}, J_{5^{\prime} \mathrm{a} 5^{\prime} \mathrm{b}}=-12.0 \mathrm{~Hz}, J_{5^{\prime} \mathrm{a} 4^{\prime}}=4.5 \mathrm{~Hz}, J_{5^{\prime} \mathrm{a}-\mathrm{OH}}=4.8 \mathrm{~Hz}\right.$, $\left.\mathrm{H}-5^{\prime} \mathrm{a}\right), 3.52 \mathrm{ddd}\left(1 \mathrm{H}, J_{5^{\prime} \mathrm{b} 5^{\prime} \mathrm{a}}=-12.0 \mathrm{~Hz}, J_{5^{\prime} \mathrm{b} 4^{\prime}}=4.2 \mathrm{~Hz}, J_{5^{\prime} \mathrm{b}, \mathrm{OH}}=6.3 \mathrm{~Hz}, \mathrm{H}-5^{\prime} \mathrm{b}\right), 2.71\left(\mathrm{ddd}, 1 \mathrm{H}, J_{2^{\prime} \mathrm{a}, 1^{\prime}}=7.5\right.$ $\left.\mathrm{Hz}, J_{2^{\prime} \mathrm{a}, 3^{\prime}}=5.9 \mathrm{~Hz}, J_{2^{\prime} \mathrm{a}, 2^{\prime} \mathrm{b}}=-13.0 \mathrm{~Hz}, \mathrm{H} 2^{\prime} \mathrm{a}\right), 2.25\left(\mathrm{ddd}, 1 \mathrm{H}, J_{2^{\prime} \mathrm{b}, 1^{\prime}}=6.0 \mathrm{~Hz}, J_{2^{\prime} \mathrm{b}, 3^{\prime}}=2.8 \mathrm{~Hz}, J_{2^{\prime} \mathrm{b}, 2^{\prime} \mathrm{a}}=-13.0\right.$ $\left.\mathrm{Hz}, \mathrm{H2}{ }^{\prime} \mathrm{b}\right), 1.69$ (s, 3H, $\mathrm{CH}_{3}$-cis), 1.66 (s, 3H, $\mathrm{CH}_{3}$-trans). ${ }^{13} \mathrm{C}$ NMR (100 MHz, DMSO- $\left.d_{6}\right): \delta=154.32$ (C6), 152.26 (C2), 148.09 (C4), 139.21 (C8), $133.14\left(=\mathrm{CMe}_{2}\right), 122.07$ (CH=), 119.57 (C5), 87.96 (C1'), $83.92\left(\mathrm{C}^{\prime}\right)$, $70.93\left(\mathrm{C}^{\prime}\right), 61.86\left(\mathrm{C5}^{\prime}\right), 39.49\left(\mathrm{C} 2^{\prime}\right.$, overlapping with $\left.\mathrm{DMSO}\right), 37.67\left(\mathrm{NH}^{-} \mathrm{H}_{2}\right), 25.32\left(\mathrm{CH}_{3}\right.$ isopentenyl), $17.77\left(\mathrm{CH}_{3}\right.$ isopentenyl). HRMS: $\mathrm{m} / z[\mathrm{M}+\mathrm{H}]^{+}$calculated $\mathrm{C}_{15} \mathrm{H}_{22} \mathrm{~N}_{5} \mathrm{O}_{3}{ }^{+} 320.1717$, found 320.1720; $\mathrm{m} / \mathrm{z}$ [M-deoxyribosyl] ${ }^{+}$calculated $\mathrm{C}_{12} \mathrm{H}_{12} \mathrm{~N}_{5}{ }^{+}$204.1244, found 204.1236.

$N^{6}-\left(2-\right.$ phenylethyl)-2'-deoxyadenosine(10). Yield for two steps was $58 \%$ as a foam. $\mathrm{R}_{f} 0.06\left(\mathrm{CH}_{2} \mathrm{Cl}_{2}\right.$-EtOH, 97:3). ${ }^{1} \mathrm{H}$ NMR (400 MHz, DMSO- $d_{6}$ ): $\delta=8.32(\mathrm{~s}, 1 \mathrm{H}, \mathrm{H} 2), 8.22$ (s, $\left.1 \mathrm{H}, \mathrm{H} 8\right), 7.83$ (br s, $\left.1 \mathrm{H}, N^{6} \mathrm{H}\right), 7.35-7.15$ (m, $5 \mathrm{H}, \mathrm{Ph}), 6.35\left(\mathrm{dd}, 1 \mathrm{H}, J_{1^{\prime}, 2^{\prime} \mathrm{b}}=6.2 \mathrm{~Hz}, J_{1^{\prime}, 2^{\prime} \mathrm{a}}=7.3 \mathrm{~Hz}, \mathrm{H1} 1^{\prime}\right), 5.27\left(\mathrm{~d}, 1 \mathrm{H}, J_{\mathrm{OH}, 3^{\prime}}=3.9 \mathrm{~Hz}, 3^{\prime} \mathrm{OH}\right), 5.18(\mathrm{dd}$, $\left.1 \mathrm{H}, J_{\mathrm{OH}, 5^{\prime} \mathrm{b}}=6.4 \mathrm{~Hz}, J_{\mathrm{OH}, 5^{\prime} \mathrm{a}}=5.1 \mathrm{~Hz}, 5^{\prime} \mathrm{OH}\right), 4.44-4.36\left(\mathrm{~m}, 1 \mathrm{H}, \mathrm{H3}{ }^{\prime}\right), 3.88\left(\mathrm{ddd}, 1 \mathrm{H}, J_{4^{\prime}, 3^{\prime}}=6.6 \mathrm{~Hz}, J_{4^{\prime}, 5^{\prime} \mathrm{a}}=\right.$ $\left.4.3 \mathrm{~Hz}, J_{4^{\prime}, 5^{\prime} \mathrm{b}}=4.1 \mathrm{~Hz}, \mathrm{H} 4^{\prime}\right), 3.82-3.60\left(\mathrm{~m}, 2 \mathrm{H}, N^{6} \mathrm{HCH}_{2}\right), 3.62\left(\mathrm{ddd}, 1 \mathrm{H}, J_{5^{\prime} \mathrm{a}, 4^{\prime}}=4.3 \mathrm{~Hz}, J_{5^{\prime} \mathrm{a}, 5^{\prime} \mathrm{b}}=-12.0 \mathrm{~Hz}\right.$, $\left.J_{\mathrm{OH}, 5^{\prime} \mathrm{a}}=5.1 \mathrm{~Hz}, \mathrm{H} 5^{\prime} \mathrm{a}\right), 3.52\left(\mathrm{ddd}, 1 \mathrm{H}, J_{5^{\prime} \mathrm{b}, 4^{\prime}}=4.1 \mathrm{~Hz}, J_{5^{\prime} \mathrm{b}, 5^{\prime} \mathrm{a}}=-12.0 \mathrm{~Hz}, J_{\mathrm{OH}, 5^{\prime} \mathrm{b}}=6.4 \mathrm{~Hz}, \mathrm{H} 5^{\prime} \mathrm{b}\right), 2.92(\mathrm{dd}$, $\left.2 \mathrm{H}, J_{\mathrm{CH} 2-\mathrm{CH} 2}=7.8 \mathrm{~Hz}, J_{\mathrm{CH} 2-\mathrm{CH} 2}=7.0 \mathrm{~Hz}, \underline{\mathrm{CH}_{2}} \mathrm{Ph}\right), 2.72\left(\mathrm{ddd}, 1 \mathrm{H}, J_{2^{\prime} \mathrm{a}, 1^{\prime}}=7.3 \mathrm{~Hz}, J_{2^{\prime} \mathrm{a}, 3^{\prime}}=5.6 \mathrm{~Hz}, J_{2^{\prime} \mathrm{a}, 2^{\prime} \mathrm{b}}\right.$ $\left.=-13.1 \mathrm{~Hz}, \mathrm{H} 2^{\prime} \mathrm{a}\right), 2.72\left(\mathrm{ddd}, 1 \mathrm{H}, J_{2^{\prime} \mathrm{b}, 1^{\prime}}=6.1 \mathrm{~Hz}, J_{2^{\prime} \mathrm{b}, 3^{\prime}}=2.9 \mathrm{~Hz}, J_{2^{\prime} \mathrm{b}, 2^{\prime} \mathrm{a}}=-13.1 \mathrm{~Hz}, \mathrm{H} 2^{\prime} \mathrm{a}\right) .{ }^{13} \mathrm{C} \mathrm{NMR}(100$ $\mathrm{MHz}, \mathrm{CD}_{3} \mathrm{OD}$ ): $\delta=156.21$ (C6), 153.51 (C2), 148.86 (C4), 140.93 (C8), 140.47 (Ph), $129.88(\mathrm{Ph}), 129.46(\mathrm{Ph})$, $127.31(\mathrm{Ph}), 121.30(\mathrm{C} 5), 89.91\left(\mathrm{C1}^{\prime}\right), 87.15\left(\mathrm{C} 4^{\prime}\right), 73.07\left(\mathrm{C} 3^{\prime}\right), 63.67\left(\mathrm{C}^{\prime}\right), 43.19\left(\mathrm{NHCH}_{2}\right), 41.58\left(\mathrm{C2}^{\prime}\right), 36.68$ 
$\left(\underline{\mathrm{CH}_{2}} \mathrm{Ph}\right)$. HRMS: $m / z[\mathrm{M}+\mathrm{H}]^{+}$calculated $\mathrm{C}_{18} \mathrm{H}_{22} \mathrm{~N}_{5} \mathrm{O}_{3}{ }^{+} 356.1717$, found 356.1724; $m / z$ [M-deoxyribosyl] ${ }^{+}$ calculated $\mathrm{C}_{13} \mathrm{H}_{14} \mathrm{~N}_{5}{ }^{+}$240.1244, found 240.1241 .

$N^{6}$-benzyl-5'-deoxyadenosine(12). Yield for two steps was $77 \%$ as a powder. $\mathrm{R}_{f} 0.32\left(\mathrm{CH}_{2} \mathrm{Cl}_{2}-\mathrm{EtOH}, 95: 5\right)$. m.p. 198-201 ${ }^{\circ} \mathrm{C} .{ }^{1} \mathrm{H}$ NMR $\left(400 \mathrm{MHz}\right.$, DMSO- $\left.d_{6}\right): \delta=8.29-8.37\left(\mathrm{~m}, 2 \mathrm{H}, \mathrm{H}-2, N^{6} \mathrm{H}\right), 8.21(\mathrm{~s}, 1 \mathrm{H}, \mathrm{H}-8), 7.16-7.37$ $(\mathrm{m}, 5 \mathrm{H}, \mathrm{Ph}), 5.85\left(\mathrm{dd}, 1 \mathrm{H}, J_{1^{\prime}-2^{\prime}}=4.77 \mathrm{~Hz}, J_{1^{\prime}-2^{\prime} \mathrm{OH}}=2.54 \mathrm{~Hz}, \mathrm{H1} 1^{\prime}\right), 5.38\left(\mathrm{~d}, 1 \mathrm{H}, J_{3^{\prime}-\mathrm{OH}}=5.25 \mathrm{~Hz}, 3^{\prime} \mathrm{OH}\right), 5.10$ $\left(\mathrm{d}, 1 \mathrm{H}, J_{2^{\prime}-\mathrm{OH}}=4.61 \mathrm{~Hz}, 2^{\prime} \mathrm{OH}\right), 4.60-4.83\left(\mathrm{~m}, 3 \mathrm{H}, \mathrm{H} 2^{\prime}, \mathrm{NHCH}_{2}\right), 3.93-4.10\left(\mathrm{~m}, 2 \mathrm{H}, \mathrm{H} 3^{\prime}, \mathrm{H} 4^{\prime}\right), 1.30$ (dd, 3H, $\left.J_{\mathrm{CH} 3-4^{\prime}}=4.77 \mathrm{~Hz}, J_{\mathrm{CH} 3-3^{\prime} \mathrm{OH}}=1.4 \mathrm{~Hz}, \mathrm{CH}_{3}\right) .{ }^{13} \mathrm{C} \mathrm{NMR}\left(100 \mathrm{MHz}, \mathrm{DMSO}-d_{6}\right): \delta=154.47(\mathrm{C} 6), 152.54(\mathrm{C} 2)$, $148.79(\mathrm{C} 4), 140.04(\mathrm{Ph}), 139.82(\mathrm{C} 8), 128.14(\mathrm{Ph}), 127.08(\mathrm{Ph}), 126.54(\mathrm{Ph}), 119.51(\mathrm{C} 5), 87.92\left(\mathrm{C1}^{\prime}\right), 79.71\left(\mathrm{C4}^{\prime}\right)$, $74.59\left(\mathrm{C}^{\prime}\right), 73.05\left(\mathrm{C}^{\prime}\right), 42.89\left(\mathrm{CH}_{2} \mathrm{Ph}\right), 16.89\left(\mathrm{CH}_{3}\right)$. HRMS: $\mathrm{m} / z[\mathrm{M}+\mathrm{H}]^{+}$calculated $\mathrm{C}_{17} \mathrm{H}_{20} \mathrm{~N}_{5} \mathrm{O}_{3}{ }^{+} 342.1561$, found 342.1566; $\mathrm{m} / z$ [M-deoxyribosyl] ${ }^{+}$calculated $\mathrm{C}_{12} \mathrm{H}_{12} \mathrm{~N}_{5}{ }^{+}$226.1087, found 226.1086 .

$N^{6}$-isopentenyl-5'-deoxyadenosine(13). Yield for two steps was $47 \%$ as a powder. $\mathrm{R}_{f} 0.31\left(\mathrm{CH}_{2} \mathrm{Cl}_{2}-\mathrm{EtOH}, 95: 5\right)$. m.p. $117-120{ }^{\circ} \mathrm{C} .{ }^{1} \mathrm{H}$ NMR $\left(400 \mathrm{MHz}, \mathrm{DMSO}-d_{6}\right): \delta=8.29$ (s, $\left.1 \mathrm{H}, \mathrm{H} 2\right), 8.21(\mathrm{~s}, 1 \mathrm{H}, \mathrm{H} 8), 7.77(\mathrm{br} \mathrm{s}, 1 \mathrm{H}$, $\left.N^{6} \mathrm{H}\right), 5.84\left(\mathrm{~d}, 1 \mathrm{H}, J_{1^{\prime}-2^{\prime}}=4.8 \mathrm{~Hz}, \mathrm{H1}^{\prime}\right), 5.38\left(\mathrm{~d}, 1 \mathrm{H}, J_{2^{\prime}-\mathrm{OH}}=5.6 \mathrm{~Hz}, 2^{\prime} \mathrm{OH}\right), 5.30\left(\mathrm{tq}, 1 \mathrm{H}, J_{\mathrm{CH}-\mathrm{CH} 2}=6.6 \mathrm{~Hz}\right.$, $\left.J_{\mathrm{CH}-\mathrm{CH} 3}=1.3 \mathrm{~Hz}, \mathrm{CH}=\right), 5.10\left(\mathrm{~d}, 1 \mathrm{H}, J_{3^{\prime}-\mathrm{OH}}=5.3 \mathrm{~Hz}, 3^{\prime} \mathrm{OH}\right), 4.65\left(\mathrm{ddd}, 1 \mathrm{H}, J_{2^{\prime}-3^{\prime}}=4.6 \mathrm{~Hz}, J_{2^{\prime}-1^{\prime}}=4.8 \mathrm{~Hz}\right.$, $\left.J_{2^{\prime}-\mathrm{OH}}=5.6 \mathrm{~Hz}, \mathrm{H} 2^{\prime}\right), 4.08\left(\mathrm{br} \mathrm{s}, 2 \mathrm{H}, N^{6} \mathrm{HCH}_{2}\right), 3.93-4.01\left(\mathrm{~m}, 2 \mathrm{H}, \mathrm{H}^{\prime}, \mathrm{H}^{\prime}\right), 1.70\left(\mathrm{~d}, 3 \mathrm{H}, J_{\mathrm{CH} 3-\mathrm{CH}}=0.5 \mathrm{~Hz}\right.$, $\mathrm{CH}_{3}$-cis $), 1.67\left(\mathrm{~d}, 3 \mathrm{H}, J_{\mathrm{CH} 3-\mathrm{CH}}=0.8 \mathrm{~Hz}, \mathrm{CH}_{3}\right.$-trans $), 1.30\left(\mathrm{~d}, 3 \mathrm{H}, J_{\mathrm{CH} 3-\mathrm{CH}}=6.2 \mathrm{~Hz}, \mathrm{CH}_{3}\right) .{ }^{13} \mathrm{C} \mathrm{NMR}(100$ MHz, DMSO- $\left.d_{6}\right): \delta=154.30$ (C6), $152.53(\mathrm{C} 2), 148.43(\mathrm{C} 4), 139.53(\mathrm{C} 8), 133.11\left(\mathrm{CMe}_{2}\right), 122.13(\mathrm{CH}=), 119.52$ (C5), $87.84\left(\mathrm{C1}^{\prime}\right), 79.63\left(\mathrm{C}^{\prime}\right), 74.57\left(\mathrm{C}^{\prime}\right), 73.05\left(\mathrm{C}^{\prime}\right), 37.67\left(\mathrm{NHCH}_{2}\right), 25.33\left(\mathrm{CH}_{3}\right), 18.86\left(\mathrm{CH}_{3}\right.$ isopentenyl), $17.79\left(\mathrm{CH}_{3}\right.$ isopentenyl). HRMS: $\mathrm{m} / z[\mathrm{M}+\mathrm{H}]^{+}$calculated $\mathrm{C}_{15} \mathrm{H}_{22} \mathrm{~N}_{5} \mathrm{O}_{3}{ }^{+} 320.1717$, found 320.1723; $\mathrm{m} / \mathrm{z}$ [M-deoxyribosyl] ${ }^{+}$calculated $\mathrm{C}_{12} \mathrm{H}_{12} \mathrm{~N}_{5}{ }^{+}$204.1244, found 204.1240.

\subsubsection{Typical Procedure for Preparation of Nucleosides by Mitsunobu Reaction with Alcohols}

To the solution of $N^{6}$-acetyl-2', $3^{\prime}, 5^{\prime}$-tri-O-acetyladenosine (1) or $N^{6}$-acetyl-3 $3^{\prime}, 5^{\prime}$-di-O-acetyl-2' -deoxyadenosine (2) or $\mathrm{N}^{6}$-acetyl-2, $3^{\prime}$-di-O-acetyl-5'-deoxyadenosine (3) (1 mmol) with triphenylphosphine $\left(\mathrm{Ph}_{3} \mathrm{P}\right)(2 \mathrm{mmol})$ and corresponding alcohol $(2 \mathrm{mmol})$ in tetrahydrofuran (THF) $(5 \mathrm{~mL})$ diethyl azodicarboxylate (DEAD) $(2 \mathrm{mmol})$ was added in one portion and the solution was kept at r.t. for $48 \mathrm{~h}$. The reaction was monitored by TLC (silica gel, $\mathrm{CH}_{2} \mathrm{Cl}_{2}-\mathrm{EtOH}, 97: 3$ ). After $48 \mathrm{~h}$ the reaction mixture was concentrated in vacuo and the residue was dissolved in $\mathrm{CH}_{2} \mathrm{Cl}_{2}$ and washed with brine $(3 \times 20 \mathrm{~mL})$. The organic layer was separated, dried over anhydrous sodium sulfate, filtered, and concentrated in vacuo. The residue was purified by column chromatography (silica gel, $\mathrm{CH}_{2} \mathrm{Cl}_{2}-\mathrm{EtOH}$, 97:3). Partially purified compound was dissolved in $4 \mathrm{M} \mathrm{n}-\mathrm{PrNH}_{2}$ in $\mathrm{MeOH}$ solution $(50 \mathrm{mmol})$ and left at r.t. for $24 \mathrm{~h}$, after which the mixture was concentrated in vacuo and the residue was purified by column chromatography on silica gel. The column was washed with $\mathrm{CH}_{2} \mathrm{Cl}_{2}-\mathrm{EtOH}$, 95:5, the product was eluted with $\mathrm{CH}_{2} \mathrm{Cl}_{2}-\mathrm{EtOH}, 90: 10$. The resulting product was dried for $24 \mathrm{hrs}$ in a vacuum desiccator over phosphorous pentaoxide $\left(\mathrm{P}_{2} \mathrm{O}_{5}\right)$.

$N^{6}$-(2-phenylethyl)-adenosine (6). Yield for two steps was $65 \%$ as a powder. $\mathrm{R}_{f} 0.28\left(\mathrm{CH}_{2} \mathrm{Cl}_{2}\right.$-EtOH, 9:1 $v / v)$. m.p. $169-171{ }^{\circ} \mathrm{C} .{ }^{1} \mathrm{H}$ NMR $\left(400 \mathrm{MHz}\right.$, DMSO- $\left.d_{6}\right): \delta=8.34$ (s, $\left.1 \mathrm{H}, \mathrm{H} 8\right), 8.23$ (br s, $\left.1 \mathrm{H}, \mathrm{H} 2\right), 7.88$ (br $\left.\mathrm{s}, 1 \mathrm{H}, N^{6} \mathrm{H}\right), 7.16-7.33(\mathrm{~m}, 5 \mathrm{H}, \mathrm{Ph}), 5.89\left(\mathrm{~d}, 1 \mathrm{H}, J_{1^{\prime}, 2^{\prime}}=6.1 \mathrm{~Hz}, \mathrm{H} 1^{\prime}\right), 5.41\left(\mathrm{~d}, 1 \mathrm{H}, J_{\mathrm{OH}-2^{\prime}}=6.1 \mathrm{~Hz}, 2^{\prime} \mathrm{OH}\right)$, $5.36\left(\mathrm{dd}, 1 \mathrm{H}, J_{\mathrm{OH}-5^{\prime} \mathrm{b}}=7.0 \mathrm{~Hz}, J_{\mathrm{OH}-5^{\prime} \mathrm{a}}=4.6 \mathrm{~Hz}, 5^{\prime} \mathrm{OH}\right), 5.15\left(\mathrm{~d}, 1 \mathrm{H}, J_{\mathrm{OH}-3^{\prime}}=4.6 \mathrm{~Hz}, 3^{\prime} \mathrm{OH}\right), 4.60(\mathrm{dd}, 1 \mathrm{H}$, $\left.J_{2^{\prime}, 3^{\prime}}=5.9 \mathrm{~Hz}, J_{2^{\prime}, 1^{\prime}}=6.1 \mathrm{~Hz}, \mathrm{H} 2^{\prime}\right), 4.15\left(\mathrm{ddd}, 1 \mathrm{H}, J_{3^{\prime}, 4^{\prime}}=3.2 \mathrm{~Hz}, J_{3^{\prime}, 2^{\prime}}=5.9 \mathrm{~Hz}, J_{3^{\prime}, \mathrm{OH}}=4.6 \mathrm{~Hz}, \mathrm{H} 3^{\prime}\right), 3.97$ $\left(\mathrm{ddd}, 1 \mathrm{H}, J_{4^{\prime}, 5^{\prime} \mathrm{b}}=3.0, J_{4^{\prime}, 5^{\prime} \mathrm{a}}=3.4, J_{4^{\prime}, 3^{\prime}}=3.2, \mathrm{H} 4^{\prime}\right), 3.63-3.81\left(\mathrm{~m}, 3 \mathrm{H}, N^{6} \mathrm{HC}_{2}, \mathrm{H} 5^{\prime} \mathrm{a}\right), 3.55(\mathrm{ddd}, 1 \mathrm{H}$, $\left.J_{5^{\prime} \mathrm{b}, 5^{\prime} \mathrm{a}}=-12.0 \mathrm{~Hz}, J_{5^{\prime} \mathrm{b}, 4^{\prime}}=3.4 \mathrm{~Hz}, J_{5^{\prime} \mathrm{b}, \mathrm{OH}}=7.0 \mathrm{~Hz}, \mathrm{H} 5^{\prime} \mathrm{b}\right), 2.93\left(\mathrm{t}, 2 \mathrm{H}, J_{\mathrm{CH} 2-\mathrm{CH} 2}=7.5 \mathrm{~Hz}, \mathrm{CH}_{2} \mathrm{Ph}\right) .{ }^{13} \mathrm{C}$ NMR (100 MHz, DMSO- $d_{6}$ ): $\delta=154.61$ (C6), 152.35 (C2), 148.27 (C4), 139.70 (C8), 139.48 (Ph), 128.63 $(\mathrm{Ph}), 128.27(\mathrm{Ph}), 126.00(\mathrm{Ph}), 119.74(\mathrm{C} 5), 87.94\left(\mathrm{C1}^{\prime}\right), 85.88\left(\mathrm{C}^{\prime}\right), 73.49\left(\mathrm{C}^{\prime}\right), 70.63\left(\mathrm{C}^{\prime}\right), 61.66\left(\mathrm{C} 5^{\prime}\right)$, $41.23\left(\mathrm{NCH}_{2}\right), 34.39\left(\mathrm{CH}_{2} \mathrm{Ph}\right)$. HRMS: $m / z[\mathrm{M}+\mathrm{H}]^{+}$calculated $\mathrm{C}_{18} \mathrm{H}_{22} \mathrm{~N}_{5} \mathrm{O}_{4}{ }^{+}$372.1666, found 372.1666.

$N^{6}$-furfuryladenosine (7). Yield for two steps was $64 \%$ as a powder. $\mathrm{R}_{f}=0.33\left(\mathrm{CH}_{2} \mathrm{Cl}_{2}-\mathrm{EtOH}, 90: 10\right)$. m.p. 150-155 ${ }^{\circ} \mathrm{C} .{ }^{1} \mathrm{H}$ NMR (400 MHz, DMSO-d6): $\delta=8.36 \mathrm{~s}(1 \mathrm{H}, \mathrm{H}-8), 8.23 \mathrm{br} \mathrm{s}\left(1 \mathrm{H}, N^{6} \mathrm{H}\right), 8.23 \mathrm{~s}(1 \mathrm{H}, \mathrm{H}-2), 7.52$ $\mathrm{dd}\left(1 \mathrm{H},{ }^{3} \mathrm{~J}=3.1 \mathrm{~Hz},{ }^{4} J=1.9 \mathrm{~Hz}, \mathrm{H} 5_{\text {Fur }}\right), 6.35 \mathrm{dd}\left(1 \mathrm{H},{ }^{3} J=3.1 \mathrm{~Hz},{ }^{3} J=1.9 \mathrm{~Hz}, \mathrm{H} 4\right.$ Fur $), 6.23 \mathrm{dd}\left(1 \mathrm{H},{ }^{3} J=3.1 \mathrm{~Hz}\right.$, 
$\left.{ }^{4} J=0.7 \mathrm{~Hz}, \mathrm{H} 3_{\text {Fur }}\right), 5.89 \mathrm{~d}\left(1 \mathrm{H}, J_{1^{\prime} 2^{\prime}}=6.2 \mathrm{~Hz}, \mathrm{H}-1^{\prime}\right), 5.41 \mathrm{~d}\left(1 \mathrm{H}, J_{\mathrm{OH}, 2^{\prime}}=6.2 \mathrm{~Hz}, 2^{\prime}-\mathrm{OH}\right), 5.34 \mathrm{dd}\left(1 \mathrm{H}, J_{\mathrm{OH}, 5^{\prime} \mathrm{b}}=\right.$ $\left.7.0 \mathrm{~Hz}, J_{\mathrm{OH}, 5^{\prime} \mathrm{a}}=4.6 \mathrm{~Hz}, 5^{\prime}-\mathrm{OH}\right), 5.15 \mathrm{~d}\left(1 \mathrm{H}, J_{\mathrm{OH}, 3^{\prime}}=4.8 \mathrm{~Hz}, 3^{\prime}-\mathrm{OH}\right), 4.71 \mathrm{br} \mathrm{s}\left(2 \mathrm{H}, N^{6} \mathrm{HC}_{2}\right), 4.61 \mathrm{ddd}(1 \mathrm{H}$, $\left.J_{2^{\prime} 3^{\prime}}=4.9 \mathrm{~Hz}, J_{2^{\prime} 1^{\prime}}=6.2 \mathrm{~Hz}, J_{2^{\prime} \mathrm{OH}}=6.2 \mathrm{~Hz}, \mathrm{H}-2^{\prime}\right), 4.15 \mathrm{ddd}\left(1 \mathrm{H}, J_{3^{\prime} 4^{\prime}}=3.0 \mathrm{~Hz}, J_{3^{\prime} 2^{\prime}}=4.9 \mathrm{~Hz}, J_{3^{\prime} \mathrm{OH}}=4.8 \mathrm{~Hz}\right.$, $\left.\mathrm{H}-3^{\prime}\right), 3.97 \mathrm{ddd}\left(1 \mathrm{H}, J_{4^{\prime} 5^{\prime} \mathrm{b}}=3.9 \mathrm{~Hz}, J_{4^{\prime} 5^{\prime} \mathrm{a}}=3.9 \mathrm{~Hz}, J_{4^{\prime} 3^{\prime}}=3.0 \mathrm{~Hz}, \mathrm{H}-4^{\prime}\right), 3.67 \mathrm{ddd}\left(1 \mathrm{H}, J_{5^{\prime} \mathrm{a} 5^{\prime} \mathrm{b}}=-12.0 \mathrm{~Hz}\right.$, $\left.J_{5^{\prime} \mathrm{a} 4^{\prime}}=3.9 \mathrm{~Hz}, J_{5^{\prime} \mathrm{a}, \mathrm{OH}}=4.6 \mathrm{~Hz}, \mathrm{H}-5^{\prime} \mathrm{a}\right), 3.56 \mathrm{ddd}\left(1 \mathrm{H}, J_{5^{\prime} \mathrm{b} 5^{\prime} \mathrm{a}}=-12.0 \mathrm{~Hz}, J_{5^{\prime} \mathrm{b} 4^{\prime}}=3.9 \mathrm{~Hz}, J_{5^{\prime} \mathrm{b}, \mathrm{OH}}=7.0 \mathrm{~Hz}\right.$, H-5'b). ${ }^{13} \mathrm{C}$ NMR (100 MHz, DMSO-d6): $\delta=154.41$ (C-6), 152.88 (Fur), 152.30 (C-2), 148.68 (C-4), 141.87 (Fur), 140.03 (C-8), 119.85 (C-5), 110.50 (Fur), 106.73 (Fur), 88.01 (C-1'), 85.93 (C-4'), 73.59 (C-2'), 70.66 (C-3'), $61.69\left(\mathrm{C}-5^{\prime}\right), 36.62\left(\mathrm{NHCH}_{2}\right)$. HRMS: $\mathrm{m} / z$ [M + H] calculated $\mathrm{C}_{15} \mathrm{H}_{18} \mathrm{~N}_{5} \mathrm{O}_{5}{ }^{+}$348.1302, found 348.1307.

$N^{6}$-furfuryl-2'-deoxyadenosine (11). Yield for two steps was $58 \%$ as a foam. $\mathrm{R}_{f} 0.52\left(\mathrm{CH}_{2} \mathrm{Cl}_{2}-\mathrm{EtOH}, 95: 5\right)$. ${ }^{1} \mathrm{HNMR}\left(400 \mathrm{MHz}, \mathrm{DMSO}-d_{6}\right): \delta=8.36 \mathrm{~s}(1 \mathrm{H}, \mathrm{H}-2), 8.23 \mathrm{br} \mathrm{s}\left(2 \mathrm{H}, \mathrm{H}-8, N^{6} \mathrm{H}\right), 7.53 \mathrm{dd}\left(1 \mathrm{H}, J_{\mathrm{H} 2-\mathrm{H} 3}=1.8 \mathrm{~Hz}\right.$, $J_{\mathrm{H} 2-\mathrm{H} 4}=0.9 \mathrm{~Hz}, \mathrm{H} 2$-furan), $6.39-6.33 \mathrm{~m}\left(2 \mathrm{H}, \mathrm{H}-1^{\prime}, \mathrm{H} 3-\right.$ furan $), 6.23 \mathrm{dd}\left(1 \mathrm{H}, J_{\mathrm{H} 4-\mathrm{H} 3}=3.2 \mathrm{~Hz}\right.$, $J_{\mathrm{H} 4-\mathrm{H} 2}=0.9 \mathrm{~Hz}, \mathrm{H} 4$-furan), $5.29 \mathrm{~d}\left(1 \mathrm{H}, J_{\mathrm{OH}-3^{\prime}}=3.9 \mathrm{~Hz}, 3-\mathrm{OH}^{\prime}\right), 5.16 \mathrm{dd}\left(1 \mathrm{H}, J_{\mathrm{OH}-5^{\prime} \mathrm{b}}=6.2 \mathrm{~Hz}\right.$, $\left.J_{\mathrm{OH}-5^{\prime} \mathrm{a}}=4.4 \mathrm{~Hz}, 5-\mathrm{OH}^{\prime}\right), 4.72 \mathrm{br} \mathrm{s}\left(2 \mathrm{H}, N^{6} \mathrm{HC}_{2}\right), 4.41$ dddd $\left(1 \mathrm{H}, J_{3^{\prime}-4^{\prime}}=2.7 \mathrm{~Hz}, J_{3^{\prime}-2^{\prime} \mathrm{a}}=5.8 \mathrm{~Hz}\right.$, $\left.J_{3^{\prime}-2^{\prime} \mathrm{b}}=2.8 \mathrm{~Hz}, J_{3^{\prime}-\mathrm{OH}}=3.9 \mathrm{~Hz}, \mathrm{H}-3^{\prime}\right), 3.89 \mathrm{ddd}\left(1 \mathrm{H}, J_{4^{\prime}-5^{\prime} \mathrm{b}}=6.9 \mathrm{~Hz}, J_{4^{\prime}-5^{\prime} \mathrm{a}}=4.6 \mathrm{~Hz}, J_{4^{\prime}-3^{\prime}}=2.7 \mathrm{~Hz}\right.$, $\left.\mathrm{H}-4^{\prime}\right), 3.62$ ddd $\left(1 \mathrm{H}, J_{5^{\prime} \mathrm{a}-5^{\prime} \mathrm{b}}=-11.7 \mathrm{~Hz}, J_{5^{\prime} \mathrm{a}-4^{\prime}}=4.6 \mathrm{~Hz}, J_{5^{\prime} \mathrm{a}-\mathrm{OH}}=6.2 \mathrm{~Hz}, \mathrm{H}-5^{\prime} \mathrm{a}\right), 3.52$ ddd $(1 \mathrm{H}$, $\left.J_{5^{\prime} \mathrm{b} 5^{\prime} \mathrm{a}}=-11.7 \mathrm{~Hz}, J_{5^{\prime} \mathrm{b} 4^{\prime}}=6.9 \mathrm{~Hz}, J_{5^{\prime} \mathrm{b}, \mathrm{OH}}=4.4 \mathrm{~Hz}, \mathrm{H}-5^{\prime} \mathrm{b}\right), 2.73 \mathrm{ddd}\left(1 \mathrm{H}, J_{2^{\prime} \mathrm{a}-1^{\prime}}=7.8 \mathrm{~Hz}, J_{2^{\prime} \mathrm{a}-3^{\prime}}=5.8 \mathrm{~Hz}\right.$, $\left.J_{2^{\prime} \mathrm{a}-2^{\prime} \mathrm{b}}=-13.2 \mathrm{~Hz}, \mathrm{H} 2^{\prime} \mathrm{a}\right), 2.25 \mathrm{ddd}\left(1 \mathrm{H}, J_{2^{\prime} \mathrm{b}-1^{\prime}}=6.1 \mathrm{~Hz}, J_{2^{\prime} \mathrm{b}-3^{\prime}}=2.8 \mathrm{~Hz}, J_{2^{\prime} \mathrm{b}-2^{\prime} \mathrm{a}}=-13.2 \mathrm{~Hz}, \mathrm{H} 2^{\prime} \mathrm{b}\right) .{ }^{13} \mathrm{C}$ NMR (100 MHz, CDCl $)_{3}$ ): $\delta=154.90$ (C-6), 152.59 (C-2), 151.48 (C-4), 142.45 (C-8), 139.79 (Fur), 121.50 (C-5), 110.60 (Fur), 107.81 (Fur), $89.83\left(\mathrm{C}-1^{\prime}\right), 87.86\left(\mathrm{C}-4^{\prime}\right), 73.43\left(\mathrm{C}-3^{\prime}\right), 63.56\left(\mathrm{C}-5^{\prime}\right), 40.98\left(\mathrm{C}-2^{\prime}\right), 37.72$ $\left(\mathrm{NHCH}_{2}\right)$. HRMS: $m / z[\mathrm{M}+\mathrm{H}]^{+}$calculated $\mathrm{C}_{15} \mathrm{H}_{18} \mathrm{~N}_{5} \mathrm{O}_{4}{ }^{+} 332.1353$, found 332.1350.

$N^{6}$-(2-phenylethyl)-5'-deoxyadenosine (14). Yield for two steps was $54 \%$ as a powder; $\mathrm{R}_{f} 0.30$ $\left(\mathrm{CH}_{2} \mathrm{Cl}_{2}-\mathrm{EtOH}, 95: 5\right)$. m.p. $161-163{ }^{\circ} \mathrm{C} .{ }^{1} \mathrm{H}$ NMR (DMSO- $\left.d_{6}\right): \delta=8.30(\mathrm{~s}, 1 \mathrm{H}, \mathrm{H} 2), 8.24(\mathrm{~s}, 1 \mathrm{H}$, $\mathrm{H} 8), 7.79\left(\mathrm{br} \mathrm{s}, 1 \mathrm{H}, N^{6} \mathrm{H}\right), 7.15-7.40(\mathrm{~m}, 5 \mathrm{H}, \mathrm{Ph}), 5.85\left(\mathrm{~d}, 1 \mathrm{H}, J_{1^{\prime}-2^{\prime}}=4.9 \mathrm{~Hz}, \mathrm{H} 1^{\prime}\right), 5.38(\mathrm{~d}, 1 \mathrm{H}$, $\left.J_{3^{\prime}-\mathrm{OH}}=5.57 \mathrm{~Hz}, 3^{\prime} \mathrm{OH}\right), 5.10\left(\mathrm{~d}, 1 \mathrm{H}, J_{2^{\prime}-\mathrm{OH}}=5.1 \mathrm{~Hz}, 2^{\prime} \mathrm{OH}\right), 4.66\left(\mathrm{ddd}, 1 \mathrm{H}, J_{2^{\prime}-1^{\prime}}=4.9 \mathrm{~Hz}, J_{2^{\prime}-3^{\prime}}=4.5 \mathrm{~Hz}\right.$, $\left.J_{2^{\prime}-\mathrm{OH}^{\prime}}=5 \mathrm{~Hz}, \mathrm{H} 2^{\prime}\right), 3.92-4.02\left(\mathrm{~m}, 2 \mathrm{H}, \mathrm{H}^{\prime}, \mathrm{H}^{\prime}\right), 3.72\left(\mathrm{br} \mathrm{s}, 2 \mathrm{H}, \mathrm{NHC}_{2}\right), 2.93\left(\mathrm{t}, 2 \mathrm{H}, J_{\mathrm{CH} 2-\mathrm{CH} 2}=7 \mathrm{~Hz}\right.$, $\left.\underline{\mathrm{CH}}_{2} \mathrm{Ph}\right), 1.31\left(\mathrm{~d}, 3 \mathrm{H}, J_{\mathrm{CH} 3-4^{\prime}}=6.04 \mathrm{~Hz}, \mathrm{CH}_{3}\right) .{ }^{13} \mathrm{C} \mathrm{NMR}\left(\mathrm{DMSO}-d_{6}\right): \delta=154.50(\mathrm{C} 6), 152.58(\mathrm{C} 2), 148.61$ (C4), $139.62(\mathrm{C} 8, \mathrm{Ph}), 128.62(\mathrm{Ph}), 128.25(\mathrm{Ph}), 125.98(\mathrm{Ph}), 119.54(\mathrm{C} 5), 87.85\left(\mathrm{C1}^{\prime}\right), 79.67\left(\mathrm{C}^{\prime}\right), 74.59\left(\mathrm{C}^{\prime}\right)$, $73.07\left(\mathrm{C3}^{\prime}\right), 41.25\left(\underline{\mathrm{CH}_{2}} \mathrm{Ph}\right), 35.01\left(\mathrm{NHCH}_{2}\right), 18.88\left(\mathrm{CH}_{3}\right)$. HRMS: $\mathrm{m} / z[\mathrm{M}+\mathrm{H}]^{+}$calculated $\mathrm{C}_{18} \mathrm{H}_{22} \mathrm{~N}_{5} \mathrm{O}_{3}{ }^{+}$ 356.1717, found 356.1727; $\mathrm{m} / \mathrm{z}$ [M-deoxyribosyl] ${ }^{+}$calculated $\mathrm{C}_{13} \mathrm{H}_{14} \mathrm{~N}_{5}{ }^{+} 240.1244$, found 240.1243.

$N^{6}$-furfuryl-5'-deoxyadenosine (15). Yield for two steps was $73 \%$ as a powder; $\mathrm{R}_{f} 0.24\left(\mathrm{CH}_{2} \mathrm{Cl}_{2}-\mathrm{EtOH}\right.$, 97:3). m.p. $185-188^{\circ} \mathrm{C} .{ }^{1} \mathrm{H}$ NMR (DMSO- $\left.d_{6}\right): \delta=8.34 \mathrm{~s}(1 \mathrm{H}, \mathrm{H}-2), 8.25 \mathrm{~s}(1 \mathrm{H}, \mathrm{H} 8), 8.22 \mathrm{br} \mathrm{s}\left(1 \mathrm{H}, N^{6} \mathrm{H}\right)$, $7.53 \mathrm{dd}\left(1 \mathrm{H}, J_{\mathrm{H} 2-\mathrm{H} 3}=1.7 \mathrm{~Hz}, J_{\mathrm{H} 2-\mathrm{H} 4}=0.8 \mathrm{~Hz}, \mathrm{H} 2\right.$-furan $), 6.36 \mathrm{dd}\left(1 \mathrm{H}, J_{\mathrm{H} 3-\mathrm{H} 2}=1.7 \mathrm{~Hz}, J_{\mathrm{H} 3-\mathrm{H} 4}=3.1 \mathrm{~Hz}\right.$, H3-furan), $6.23 \mathrm{dd}\left(1 \mathrm{H}, J_{\mathrm{H} 4-\mathrm{H} 3}=3.1 \mathrm{~Hz}, J_{\mathrm{H} 4-\mathrm{H} 2}=0.8 \mathrm{~Hz}, \mathrm{H} 4-\right.$ furan $), 5.86 \mathrm{~d}\left(J_{1^{\prime}-2^{\prime}}=4.9 \mathrm{~Hz}, \mathrm{H}-1^{\prime}\right), 5.41 \mathrm{~d}$ $\left(1 \mathrm{H}, J_{\mathrm{OH}-3^{\prime}}=5.7 \mathrm{~Hz}, 3-\mathrm{OH}^{\prime}\right), 5.14 \mathrm{~d}\left(1 \mathrm{H}, J_{\mathrm{OH}-2^{\prime}}=5.2 \mathrm{~Hz}, 2-\mathrm{OH}^{\prime}\right), 4.70 \mathrm{br} \mathrm{s}\left(2 \mathrm{H}, N^{6} \mathrm{HC}_{2}\right), 4.67 \mathrm{ddd}(1 \mathrm{H}$, $\left.J_{2^{\prime}-1^{\prime}}=4.9 \mathrm{~Hz}, J_{2^{\prime}-3^{\prime}}=4.5 \mathrm{~Hz}, J_{2^{\prime}-\mathrm{OH}}=5.2 \mathrm{~Hz}, \mathrm{H}-2^{\prime}\right), 4.05-3.90 \mathrm{~m}\left(\mathrm{H}-3^{\prime}, \mathrm{H}-4^{\prime}\right), 1.30 \mathrm{~d}\left(J_{\mathrm{CH} 3-\mathrm{CH}}=6.1 \mathrm{~Hz}\right.$, $\mathrm{CH}_{3}$ ). ${ }^{13} \mathrm{C}$ NMR (100 MHz, DMSO-d6): $\delta=154.27$ (C-6), 152.93 (C-4), 152.44 (C-2), 141.77 (C-8), 139.96 (Fur), 119.60 (C-5), 110.40 (Fur), 106.59 (Fur), 87.89 (C-1'), 79.72 (C-4'), 74.59 (C-2'), 73.05 (C-3'), 36.54 $\left(\mathrm{NHCH}_{2}\right), 18.90\left(\mathrm{CH}_{3}\right)$. HRMS: $m / z[\mathrm{M}+\mathrm{H}]^{+}$calculated $\mathrm{C}_{15} \mathrm{H}_{18} \mathrm{~N}_{5} \mathrm{O}_{4}{ }^{+} 332.1353$, found 332.1355.

\subsection{Cytokinin Activity Assays}

Investigated compounds were dissolved in $100 \%$ DMSO to a concentration of $0.1 \mathrm{M}$. Then these solutions were diluted with distilled water to concentrations of 1-10 $\mu \mathrm{M}$. Thus, the content of DMSO in $1 \mu \mathrm{M}$ ligand solutions was only $0.001 \%$.

CK activities were measured in two bioassays based on seedlings of Arabidopsis thaliana or Amaranthus caudatus. In the first assay, we used double mutants of Arabidopsis, in which only one of the three CK receptors (AHK2, AHK3, or CRE1/AHK4) was kept active, as well as wild type (WT) Arabidopsis seedlings with all three functioning receptors [15]. All Arabidopsis plants used, including WT control, carried the reporter GUS gene under control of CK-dependent promoter $P_{\text {ARR5 }}$ [16]. 4- to 5-day-old Arabidopsis seedlings were incubated for $16 \mathrm{~h}$ in aqueous solutions of tested compounds [17]. 
The level of CK activity of each compound was determined through the level of GUS activity, since it reflects the intensity of $P_{\text {ARR5 }}$ :GUS expression [18]. Each sample contained 10 aligned seedlings; experiments were performed in two biological replicates.

In the case of Amaranthus bioassay, 3- to 4-day-old etiolated seedlings with removed roots were incubated for $16 \mathrm{~h}$ in solutions of tested compounds in the dark. Each sample contained 10 aligned seedlings; all samples were in triplicate. The CK activity of compounds corresponds to the level of the pigment amaranthin accumulation in cotyledons, which was determined with spectrophotometer $[19,20]$.

The experiments were carried out in 2-3 biological replications. In all our experiments, probes with BA were included as positive control and its activity was set as $100 \%$. CK activity of all tested compounds was evaluated as percentage relative to the BA activity (after background subtraction) at the same concentration in the same experiment.

\section{Results and Discussion}

\subsection{Chemistry}

To synthesize desired nucleosides, we used our mild and efficient approach based on regioselective $N^{6}$-alkylation of acetyl-protected adenosine, $2^{\prime}$-deoxyadenosine and 5' -deoxyadenosine derivatives 1-3 either with alcohols under Mitsunobu reaction conditions (Scheme 1, conditions (i)) or with alkyl halides in the presence of the base (Scheme 1, conditions (ii)) [13,14]. The main advantage of these approaches is the possibility to use both alkyl halides and alcohols for $N^{6}$-modification. The following deacetylation with $\mathrm{n}-\mathrm{PrNH}_{2}$ in $\mathrm{MeOH}$ (Scheme 1, conditions (iii)) yielded the final nucleosides with high overall yields. The initial triacetyl-5'-deoxyadenosine 3 was synthesized by radical reduction of corresponding $5^{\prime}$-chloro-5'-deoxyadenosine derivative in the presence of $\mathrm{Bu}_{3} \mathrm{SnH}$ according to the literature [21].

The structure of the compounds was confirmed by ${ }^{1} \mathrm{H}$ and ${ }^{13} \mathrm{C}$ NMR spectroscopy. In addition, all compounds were characterized for purity and homogeneity by high-resolution mass spectrometry (HRMS). The obtained M/z values of the compounds correspond to the calculated $\mathrm{M} / \mathrm{z}$ values. According to HPLC, all the obtained products are individual compounds. All spectral data are presented in full in the Supplementary Information.

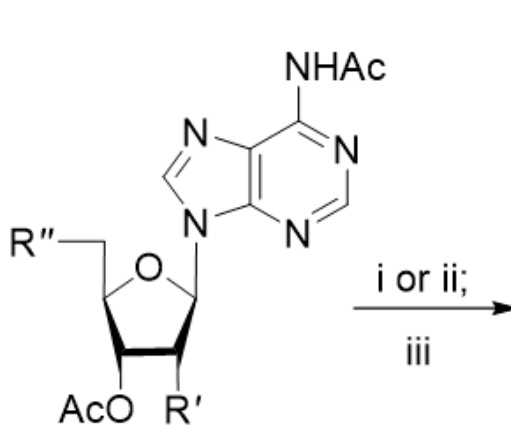<smiles></smiles>

$$
\begin{aligned}
& 1 R^{\prime}=R^{\prime \prime}=O A c \\
& 2 R^{\prime}=H, R^{\prime \prime}=O A c \\
& 3 R^{\prime}=O A c, R^{\prime \prime}=H
\end{aligned}
$$

$$
\begin{aligned}
& 4-7 R^{\prime}=R^{\prime \prime}=O H \\
& 8-11 R^{\prime}=H, R^{\prime \prime}=O H \\
& 12-15 R^{\prime}=O H, R^{\prime \prime}=H
\end{aligned}
$$

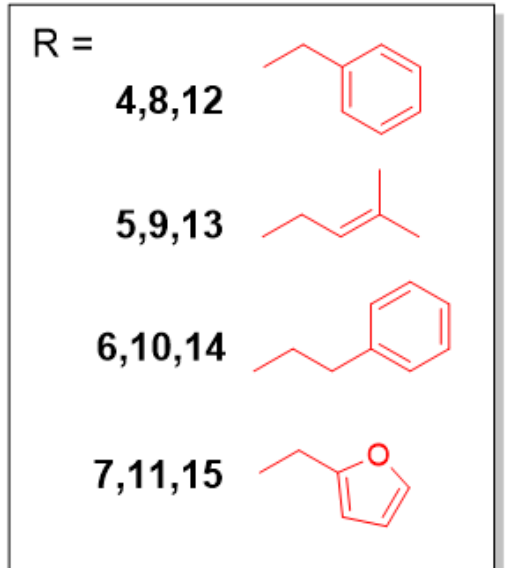

Scheme 1. Synthesis of ribo- (4-7), 2'-deoxyribo- (8-11) and 5'-deoxyribonucleoside (12-15) derivatives of CKs. Reagents and conditions: (i) $\mathrm{ROH}, \mathrm{Ph}_{3} \mathrm{P}, \mathrm{DEAD}, \mathrm{THF}, 2{ }^{\circ} \mathrm{C}, 24-48 \mathrm{~h}$; (ii) $\mathrm{RBr}, \mathrm{DBU}, \mathrm{CH}_{3} \mathrm{CN}$, r.t., 1-3 days; (iii) $4 \mathrm{M} \mathrm{n}-\mathrm{PrNH}_{2}$ in $\mathrm{MeOH}, 20^{\circ} \mathrm{C}, 24 \mathrm{~h}$.

\subsection{Cytokinin Activity}

The CK activity of all synthesized compounds was studied in two plant bioassay systems. First bioassay was based on seedlings of a model plant Arabidopsis thaliana [17]. To study the effects of CK nucleosides (as CK precursors) on different CK receptors in this assay we used double insertion 
mutants, in which only one isoform of the CK receptors (AHK2, AHK3 or CRE1/AHK4/WOL) was active in each mutant clone, as well as the wild type (WT) plants with all three functioning receptors (Table 1).

All plants were stably transformed with the GUS gene fused to CK-dependent promoter of the ARR5 gene. The hormonal activity of the compounds was determined by the level of GUS activity reflecting the intensity of the $P_{A R R 5}: G U S$ expression [17]. Based on the results of the Arabidopsis bioassay (Table 1), all tested compounds were subdivided into three conventional groups, of low, medium, and high activity. The first group included compounds whose CK activity did not exceed 30\% (colored blue), the second group included derivatives with medium activity from $30 \%$ to $80 \%$ (colored black), and the third highly active group exhibited activity above $80 \%$ (colored red) of the BA activity.

As an additional bioassay we used Amaranthus seedlings which quickly responded to CK by accumulation of the red pigment amaranthin in the dark (Table 2) [19]. This assay is rather specific and fast and considered to be a classical cytokinin bioassay [20]. As in the case of Arabidopsis bioassay compounds with activity values of less than $30 \%$ of BA activity were considered to be low active or inactive. Compounds with activity no less than $80 \%$ of BA activity were considered to be highly active.

Table 1. Cytokinin activity (in \%) of nucleoside derivatives (at two concentrations) in bioassay based on Arabidopsis thaliana double mutants. BA activity was taken as $100 \%{ }^{1}$.

\begin{tabular}{|c|c|c|c|c|c|c|}
\hline Compound & $N^{6}$-Substituent & Conc. & WT & AHK2 & AHK3 & AHK4 \\
\hline \multicolumn{7}{|c|}{ Ribonucleosides } \\
\hline $4^{*}$ & & $\begin{array}{l}10^{-5} \mathrm{M} \\
10^{-6} \mathrm{M}\end{array}$ & $\begin{array}{c}116 \pm 5 \\
75 \pm 3\end{array}$ & $\begin{array}{l}90 \pm 5 \\
94 \pm 9\end{array}$ & $\begin{array}{l}59 \pm 5 \\
77 \pm 4\end{array}$ & $\begin{array}{l}43 \pm 1 \\
51 \pm 3\end{array}$ \\
\hline $5 *$ & & $\begin{array}{l}10^{-5} \mathrm{M} \\
10^{-6} \mathrm{M}\end{array}$ & $\begin{array}{c}113 \pm 6 \\
52 \pm 6\end{array}$ & $\begin{array}{c}94 \pm 6 \\
114 \pm 5\end{array}$ & $\begin{array}{l}55 \pm 4 \\
80 \pm 4\end{array}$ & $\begin{array}{l}40 \pm 1 \\
40 \pm 5\end{array}$ \\
\hline $6 *$ & & $\begin{array}{l}10^{-5} \mathrm{M} \\
10^{-6} \mathrm{M}\end{array}$ & $\begin{array}{l}53 \pm 3 \\
28 \pm 3\end{array}$ & $\begin{array}{c}75 \pm 8 \\
38 \pm 0.5\end{array}$ & $\begin{array}{l}32 \pm 4 \\
12 \pm 1\end{array}$ & $\begin{array}{c}19 \pm 1 \\
16 \pm 0.1\end{array}$ \\
\hline 7 & & $\begin{array}{l}10^{-5} \mathrm{M} \\
10^{-6} \mathrm{M}\end{array}$ & $\begin{array}{c}78 \pm 4 \\
41 \pm 11\end{array}$ & $\begin{array}{c}90 \pm 6 \\
59 \pm 0.3\end{array}$ & $\begin{array}{l}61 \pm 4 \\
63 \pm 7\end{array}$ & $\begin{array}{r}96 \pm 12 \\
55 \pm 2.5\end{array}$ \\
\hline \multicolumn{7}{|c|}{ 2'-Deoxyribonucleosides } \\
\hline 8 & & $\begin{array}{l}10^{-5} \mathrm{M} \\
10^{-6} \mathrm{M}\end{array}$ & $\begin{array}{c}15 \pm 1 \\
10 \pm 0.5\end{array}$ & $\begin{array}{l}32 \pm 6 \\
4 \pm 0.2\end{array}$ & $\begin{array}{c}8 \pm 0.3 \\
7 \pm 1\end{array}$ & $\begin{array}{c}13 \pm 0.1 \\
2 \pm 0.1\end{array}$ \\
\hline 9 & & $\begin{array}{l}10^{-5} \mathrm{M} \\
10^{-6} \mathrm{M}\end{array}$ & $\begin{array}{c}105 \pm 4 \\
29 \pm 2\end{array}$ & $\begin{array}{c}62 \pm 10 \\
34 \pm 4\end{array}$ & $\begin{array}{l}51 \pm 4 \\
40 \pm 4\end{array}$ & $\begin{array}{c}68 \pm 5 \\
7 \pm 1\end{array}$ \\
\hline \multirow{2}{*}{10} & & $10^{-5} \mathrm{M}$ & $8 \pm 2$ & $4 \pm 0.1$ & $4 \pm 0.1$ & $3.5 \pm 0.1$ \\
\hline & & $10^{-6} \mathrm{M}$ & $8 \pm 2$ & $4 \pm 0.1$ & $3 \pm 1$ & $2 \pm 0.3$ \\
\hline \multirow{2}{*}{11} & & $10^{-5} \mathrm{M}$ & $42 \pm 2$ & $70 \pm 1$ & $4 \pm 1$ & $27 \pm 5$ \\
\hline & & $10^{-6} \mathrm{M}$ & $21 \pm 2$ & $33 \pm 1.5$ & $5 \pm 0.2$ & $25 \pm 1$ \\
\hline \multicolumn{7}{|c|}{ 5'-Deoxyribonucleosides } \\
\hline $12 *$ & & $\begin{array}{l}10^{-5} \mathrm{M} \\
10^{-6} \mathrm{M}\end{array}$ & $\begin{array}{c}22 \pm 1 \\
9 \pm 1\end{array}$ & $\begin{array}{c}12 \pm 1 \\
3 \pm 0.6\end{array}$ & $\begin{array}{c}7 \pm 0.2 \\
4 \pm 1\end{array}$ & $\begin{array}{c}6 \pm 0.4 \\
1.5 \pm 0.1\end{array}$ \\
\hline 13 * & & $\begin{array}{l}10^{-5} \mathrm{M} \\
10^{-6} \mathrm{M}\end{array}$ & $\begin{array}{l}87 \pm 7 \\
41 \pm 6\end{array}$ & $\begin{array}{l}67 \pm 9 \\
20 \pm 2\end{array}$ & $\begin{array}{c}34 \pm 5 \\
9 \pm 1\end{array}$ & $\begin{array}{l}51 \pm 2 \\
11 \pm 1\end{array}$ \\
\hline $14 *$ & & $\begin{array}{l}10^{-5} \mathrm{M} \\
10^{-6} \mathrm{M}\end{array}$ & $\begin{array}{c}15 \pm 3 \\
7+1\end{array}$ & $\begin{array}{c}10 \pm 1 \\
5+1\end{array}$ & $\begin{array}{l}14 \pm 5 \\
10+1\end{array}$ & $\begin{array}{l}4 \pm 0.2 \\
4+02\end{array}$ \\
\hline \multirow{2}{*}{15} & & $10^{-5} \mathrm{M}$ & $10 \pm 1.1$ & $13 \pm 1$ & $13 \pm 2$ & $12 \pm 0.5$ \\
\hline & & $10^{-6} \mathrm{M}$ & $8 \pm 3$ & $7 \pm 0.5$ & $7 \pm 1$ & $7 \pm 1$ \\
\hline
\end{tabular}

${ }^{1}$ Data based on three independent biological experiments. Values corresponding to low, medium, and high activities are designated by blue, black, and red, respectively. * Preliminary data for compounds 4-6 and 12-14 were published earlier [22]. 
Table 2. Cytokinin activity (in \%) of nucleoside derivatives in bioassay based on Amaranthus caudatus seedlings. BA activity was taken as $100 \%$ *.

\begin{tabular}{|c|c|c|c|}
\hline Compound & $N^{6}$-Substituent & Conc. & Relative Activity, $\%$ \\
\hline \multicolumn{4}{|c|}{ Ribonucleosides } \\
\hline 4 & & $10^{-6} \mathrm{M}$ & $64.38 \pm 10.94$ \\
\hline 5 & & $10^{-6} \mathrm{M}$ & $78.29 \pm 13.29$ \\
\hline 6 & & $10^{-6} \mathrm{M}$ & $18.69 \pm 8.22$ \\
\hline 7 & & $10^{-6} \mathrm{M}$ & $21.28 \pm 1.01$ \\
\hline \multicolumn{4}{|c|}{ 2'-Deoxyribonucleosides } \\
\hline 8 & & $10^{-6} \mathrm{M}$ & $24.08 \pm 6.94$ \\
\hline 9 & & $10^{-6} \mathrm{M}$ & $12.64 \pm 2.01$ \\
\hline 10 & & $10^{-6} \mathrm{M}$ & 0 \\
\hline 11 & & $10^{-6} \mathrm{M}$ & $21.8 \pm 5.0$ \\
\hline \multicolumn{4}{|c|}{ 5'-Deoxyribonucleosides } \\
\hline 12 & & $10^{-6} \mathrm{M}$ & 0 \\
\hline 13 & & $10^{-6} \mathrm{M}$ & 0 \\
\hline 14 & & $10^{-6} \mathrm{M}$ & 0 \\
\hline 15 & & $10^{-6} \mathrm{M}$ & $9.52 \pm 0.33$ \\
\hline
\end{tabular}

* Data based on three independent biological experiments. Values corresponding to low and medium activities are designated by blue and black, respectively.

\subsection{Analysis of Results with Arabidopsis Bioassay}

Ribosides of natural CKs 4, 5, and 7 exhibited CK effect in all experimental variants of Arabidopsis bioassay. Compounds 4, 5, and 7 exhibited the highest activity at a concentration of $10^{-5} \mathrm{M}$ for the WT, leading to nearly $100 \%$ activation of CK signaling system. 10-Fold decrease in CK concentration led to approx. twofold decrease in GUS activity activation. On the other hand, compounds 4 and 5 were more active at the more physiological concentration of $10^{-6} \mathrm{M}$ for the mutant clones (nearly $100 \%$ receptor activation for AHK2, 80\% for AHK3 and approximately 50\% for AHK4) [22]. Compound 7, a kinetin derivative, was more active at $10^{-5} \mathrm{M}$ for AHK2 and AHK4 and manifested comparable activity at both $10^{-5} \mathrm{M}$ and $10^{-6} \mathrm{M}$ for AHK3. $N^{6}$-Phenylethyladenosine (6), an artificial CK derivative, demonstrated some, though weak activity at a concentration of $10^{-6} \mathrm{M}$ only with the AHK2 receptor (Table 1). Two other receptors were inactive or very weakly active with 6 at $10^{-6} \mathrm{M}$.

Generally, as regards double mutant clones, our Arabidopsis assay makes it possible to perform a unique task, i.e. to analyze the response to CKs of individual CK receptors. In our study, the clones reacted quite uniformly, there were no case when any of CK derivatives exerted high effect with one 
receptor and simultaneously weak effect with another one. If WT plants or any of mutant clones demonstrated high CK activity (red color) with a defined compound, all other mutant clones showed with this compound the same (red) or at least medium (black) activity. Conversely, if WT plants or any of mutant clones demonstrated low/no CK activity (blue color) with some other compound, all other mutant clones with different receptors showed the same (blue) or medium (black) but never high (red) activity (Table 1). This may be a consequence of the use of the limited set of different CKs. In any case, such regularity can serve as an argument for the validity of the assay results.

$2^{\prime}$-Deoxyribo-derivative of iP (9) was active at higher concentrations $\left(10^{-5} \mathrm{M}\right)$ with all individual receptors and manifested weaker activity at more physiological concentration. $2^{\prime}$-Deoxyribo-derivatives of aromatic CKs $(8, \mathbf{1 0})$ were virtually inactive even at a concentration of $10^{-5} \mathrm{M}$ except for derivative 11 which showed some activity at both concentrations, but only with AHK2.

5'-Deoxyribo-derivative of iP (13) manifested high activity for WT, medium activity for AHK2 and AHK4 and weak activity for AHK3 at $10^{-5} \mathrm{M}$ and manifested weak activity for all individual receptors at $10^{-6} \mathrm{M}$. On the other hand, $5^{\prime}$-deoxyribo-derivatives of aromatic CKs $(\mathbf{1 2}, \mathbf{1 4}, \mathbf{1 5})$ were inactive even at a concentration of $10^{-5} \mathrm{M}$.

Taking into account these results, several inferences can be made. 5'-Deoxyribo-derivative of iP (13) cannot be phosphorylated enzymatically in vivo, thereby the LOG-mediated one-step formation of $\mathrm{iP}$ is not possible here. However, since this compound exerted the CK effect, the only way for this derivative conversion into active CK is the cleavage by adenosine nucleosidase (Figure 3A). In turn, the $5^{\prime}$-deoxyribo-derivatives of all aromatic CKs were inactive, and since the pathway associated with the action of LOG enzyme is blocked, this LOG-dependent mechanism may be suggested to play a major role in the formation of aromatic CKs (Figure 3B). For the iP nucleoside derivatives, there were no such restrictions as deoxyribo-derivatives may be able to turn in planta into free bases, at least at $10^{-5} \mathrm{M}$. Therefore, the results showed that the conversion of $5^{\prime}$-monophosphates into active CKs via LOG-mediated cleavage in Arabidopsis strongly depends on the nature of the side group (aliphatic or aromatic) of the $\mathrm{CK}$ ribosides.

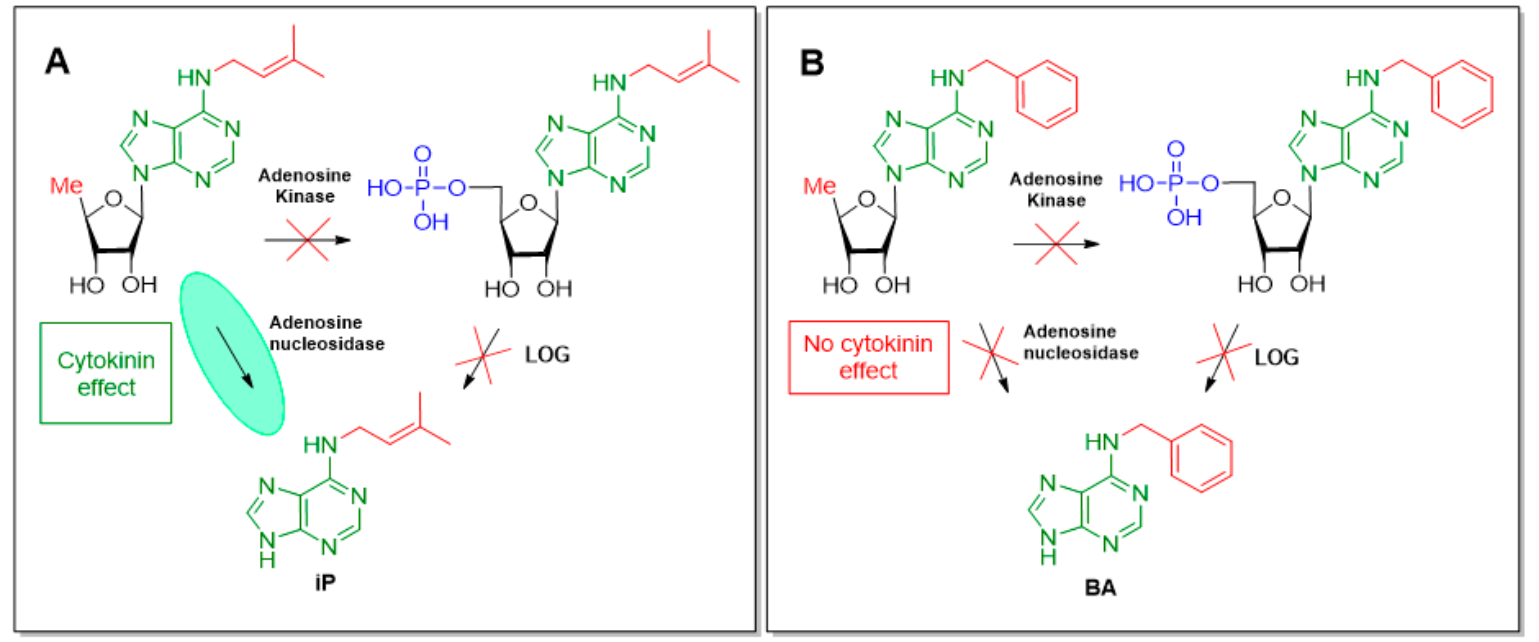

Figure 3. The effect of structural modification of cytokinin nucleosides in Arabidopsis on the biosynthesis pathways of iP (A) and BA (B).

\subsection{Analysis of Results with Amaranthus Bioassay}

In the case of Amaranthus bioassay, $N^{6}$-benzyladenosine (4) and $N^{6}$-isopentenyladenosine (5) showed pronounced CK activity, while $N^{6}$-phenylethyladenosine (6) demonstrated weak activity at $10^{-6} \mathrm{M}$ (Table 2). Contrary to Arabidopsis, in Amaranthus there were no advantage of 5 over 4 in CK activity. Besides, another aromatic CK (ribo)nucleoside $N^{6}$-furfuryladenosine (7) also showed weak activity in contrast to its medium activity in Arabidopsis bioassay. It is interesting that all 
$5^{\prime}$-deoxyribo-derivatives (12-15) as well as $2^{\prime}$-deoxyribo-derivatives (8-11) of both aromatic and isoprenoid CKs turned out to be essentially inactive in the Amaranthus bioassay. This peculiarity is indicative of a species specificity in the final step of active CK biosynthesis in plants.

It is known that adenosine nucleosidase, isolated from various sources, has a broad substrate specificity. Substrates for this enzyme may be adenosine, guanosine, inosine, xanthosine [23], $N^{6}$-benzyladenosine [24], $N^{6}$-isopentenyladenosine [25], as well as $5^{\prime}$-deoxyadenosine, 2'-deoxyadenosine [24] and several other purine nucleosides. Despite this generally accepted view, it cannot be excluded that the lack of activity of the deoxyribo-derivatives of aromatic CKs may be related to the substrate specificity of adenosine nucleosidase in this plant species. Another possible pathway for the formation of active CKs from $2^{\prime}$-deoxyribo-derivatives associated with the enzymatic phosphorylation followed by cleavage of $5^{\prime}$-monophosphates by the action of LOG also turned out to be unrealized. In that case, it may be due to the lack of $5^{\prime}$-phosphorylation of $2^{\prime}$-deoxyribo-derivatives by adenosine kinase, or due to the inability of cleavage of the corresponding $2^{\prime}$-deoxyribo-5'-monophosphates by LOG.

\section{Conclusions}

A series of nucleoside derivatives of isoprenoid $\mathrm{CK} \mathrm{N}^{6}$-isopentenyladenine and various aromatic CKs was synthesized starting from acyl-protected ribofuranosyl-, 2'-deoxyribofuranosyl- and $5^{\prime}$-deoxyribofuranosyladenine derivatives using mild and efficient stereoselective $N^{6}$-alkylation with further acyl deblocking, and their hormonal (cytokinin) activity was determined in two bioassays based on seedlings of Arabidopsis thaliana and Amaranthus caudatus. We demonstrated that ribo-, $2^{\prime}$-deoxyribo-, $5^{\prime}$-deoxyribo-derivatives of $N^{6}$-isopentenyladenine, as well as ribosides of aromatic CKs were able to transform into active CKs and exhibited hormonal activity in Arabidopsis, while $5^{\prime}$-deoxyribo- and 2'-deoxyribo-derivatives of aromatic CKs were inactive. Therefore, not only ribobut also $5^{\prime}$-deoxyribo- and 2'-deoxyribonucleosides may serve as precursors of active CKs, at least in Arabidopsis. However, in the latter case, the only way of biosynthesis of aromatic CKs seems to be the direct cleavage of $5^{\prime}$-monophosphates to active nucleobases catalyzed by phosphoribohydrolase LOG, whereas the biosynthesis of $N^{6}$-isopentenyladenine may evidently proceed also by hydrolysis of CK nucleosides catalyzed by adenosine nucleosidase. As a result, it can be concluded that the biosynthesis pathways of isoprenoid (exemplified by $N^{6}$-isopentenyladenine) and aromatic CKs may be different, at least in Arabidopsis, and that further research is needed to shed light on the mechanisms of biosynthesis of this class of compounds. Of course, at present it cannot be excluded that in other plant species the CK biosynthesis pathways are different. For example, in Amaranthus deoxyribo-derivatives of both $\mathrm{N}^{6}$-isopentenyladenine and aromatic CKs were equally low active. Taking into consideration the variety of biological effects of CKs on the growth, development, resistance and productivity of plants, the knowledge gained may contribute to the development of new approaches to handling the growth and development of plant species valuable to humans.

Supplementary Materials: The following are available online at http://www.mdpi.com/2218-273X/10/1/86/s1, ${ }^{1} \mathrm{H}$ and ${ }^{13} \mathrm{C}$ NMR spectra; High resolution mass spectra (HRMS).

Author Contributions: Conceptualization, S.N.M. and G.A.R.; experimental work, V.E.O., E.M.S. and M.S.D.; data analysis V.E.O., E.M.S., M.S.D., G.A.R. and S.N.M.; writing-original draft preparation, V.E.O.; writing-review and editing, S.N.M. and G.A.R.; supervision, S.N.M. and G.A.R.; funding acquisition, V.E.O., G.A.R. All authors have read and agreed to the published version of the manuscript.

Funding: The research was supported by the Russian Foundation for Basic Research (grants No. 18-34-00084 and 17-04-00969).

Acknowledgments: The authors thank Pavel N. Solyev (EIMB RAS) for HPLC-HRMS spectra registration. The double mutants' seeds of Arabidopsis thaliana were kindly provided by T. Schmülling and M. Riefler.

Conflicts of Interest: The authors declare no conflict of interest. 


\section{References}

1. Sakakibara, H. Cytokinins: Activity, biosynthesis, and translocation. Annu. Rev. Plant Biol. 2006, 57, 431-449. [CrossRef] [PubMed]

2. Romanov, G.A. How do cytokinins affect the cell? Rus. J. Plant Physiol. 2009, 56, 268-290. [CrossRef]

3. Miller, C.; Skoog, F.; Saltza, M.; Strong, M. Kinetin, a cell division factor from deoxyribonucleic acid. J. Am. Chem. Soc. 1955, 77, 1329-1334. [CrossRef]

4. Plihalova, L.; Vylíčilová, H.; Doležal, K.; Zahajska, L.; Zatloukal, M.; Strnad, M. Synthesis of aromatic cytokinins for plant biotechnology. New Biotech. 2016, 33, 614-624. [CrossRef]

5. Kamínek, M. Tracking the story of cytokinin research. J. Plant Growth Regul. 2015, 34, 723-739. [CrossRef]

6. Lomin, S.N.; Krivosheev, D.M.; Steklov, M.Y.; Arkhipov, D.V.; Osolodkin, D.I.; Schmülling, T.; Romanov, G.A. Plant membrane assays with cytokinin receptors underpin the unique role of free cytokinin bases as biologically active ligands. J. Exp. Bot. 2015, 66, 1851-1863. [CrossRef]

7. Savelieva, E.M.; Oslovsky, V.E.; Karlov, D.S.; Kurochkin, N.N.; Getman, I.A.; Lomin, S.N.; Sidorov, G.V.; Mikhailov, S.N.; Osolodkin, D.I.; Romanov, G.A. Cytokinin activity of $N^{6}$-benzyladenine derivatives assayed by interaction with the receptors in planta, in vitro, and in silico. Phytochemistry 2018, 149, 161-177. [CrossRef]

8. Sakakibara, H. Cytokinin biosynthesis and metabolism. In Plant Hormones, 3rd ed.; Davies, P.J., Ed.; Springer: Dordrecht, The Netherlands, 2010; pp. 95-114.

9. Komada-Nobusada, T.; Sakakibara, H. Molecular basis for cytokinin biosynthesis. Phytochemistry 2009, 70, 444-449. [CrossRef]

10. Tokunaga, H.; Kojima, M.; Kuroha, T.; Ishida, T.; Sugimoto, K.; Kiba, T.; Sakakibara, H. Arabidopsis lonely guy (LOG) multiple mutants reveal a central role of the LOG-dependent pathway in cytokinin activation. Plant J. 2012, 69, 355-365. [CrossRef]

11. Osugi, A.; Sakakibara, H. Q\&A: How do plants respond to cytokinins and what is their importance? BMC Biol. 2015, 13, 102.

12. Jordheim, L.P.; Durantel, D.; Zoulim, F.; Dumontet, C. Advances in the development of nucleoside and nucleotide analogues for cancer and viral diseases. Nat. Rev. Drug Discov. 2013, 12, 447-464. [CrossRef] [PubMed]

13. Drenichev, M.S.; Oslovsky, V.E.; Tararov, V.I.; Mikhailov, S.N. Synthesis of $N^{6}$-substituted adenosines as cytokinin nucleosides. Curr. Protoc. Nucleic Acid Chem. 2018, 72, 14.15.1-14.15.16. [CrossRef] [PubMed]

14. Drenichev, M.S.; Oslovsky, V.E.; Sun, L.; Tijsma, A.; Kurochkin, N.N.; Tararov, V.I.; Chizhov, A.O.; Neyts, J.; Pannecouque, C.; Leyssen, P.; et al. Modification of the length and structure of the linker of $N^{6}$-benzyladenosine modulates its selective antiviral activity against enterovirus 71. Eur. J. Med. Chem. 2016, 111, 84-94. [CrossRef] [PubMed]

15. Riefler, M.; Novak, O.; Strnad, M.; Schmülling, T. Arabidopsis cytokinin receptor mutants reveal functions in shoot growth, leaf senescence, seed size, germination, root development, and cytokinin metabolism. Plant Cell 2006, 18, 40-54. [CrossRef] [PubMed]

16. Stolz, A.; Riefler, M.; Lomin, S.N.; Achazi, K.; Romanov, G.A.; Schmülling, T. The specificity of cytokinin signalling in Arabidopsis thaliana is mediated by differing ligand affinities and expression profiles of the receptors. Plant J. 2011, 67, 157-168. [CrossRef] [PubMed]

17. Romanov, G.A.; Kieber, J.J.; Schmülling, T. A rapid cytokinin response assay in Arabidopsis indicates a role for phospholipase D in cytokinin signalling. FEBS Lett. 2002, 515, 39-43. [CrossRef]

18. Zvereva, S.D.; Romanov, G.A. Reporter genes for plant genetic engineering: Characteristics and detection. Russ. J. Plant Physiol. 2000, 47, 424-432.

19. Romanov, G.A.; Getman, I.A.; Schmülling, T. Investigation of early cytokinin effects in a rapid Amaranthus seedling test. Plant Growth Regul. 2000, 34, 337-344. [CrossRef]

20. Biddington, N.L.; Thomas, T.H. A modified Amaranthus betacyanin bioassay for the rapid determination of cytokinins in plant extracts. Planta 1973, 111, 183-186. [CrossRef]

21. Wang, Y.; Hogenkamp, H.P.; Long, R.A.; Revankar, G.R.; Robins, R.K. A convenient synthesis of 5'-deoxyribonucleosides. Carbohydr. Res. 1977, 59, 449-457. [CrossRef]

22. Oslovsky, V.E.; Savelieva, E.M.; Drenichev, M.S.; Romanov, G.A.; Mikhailov, S.N. Comparative analysis of the biosynthesis of isoprenoid and aromatic cytokinins. Dokl. Biochem. Biophys. 2019, 488, 346-349. [CrossRef] [PubMed] 
23. Ogawa, J.; Takeda, S.; Xie, S.X.; Hatanaka, H.; Ashikari, T.; Amachi, T.; Shimizu, S. Purification, characterization, and gene cloning of purine nucleosidase from Ochrobactrum anthropi. Appl. Environ. Microbiol. 2001, 67, 1783-1787. [CrossRef] [PubMed]

24. Abusamhadneh, E.; McDonald, N.E.; Kline, P.C. Isolation and characterization of adenosine nucleosidase from yellow lupin (Lupinus luteus). Plant Sci. 2000, 153, 25-32. [CrossRef]

25. Chen, C.M.; Kristopeit, S.M. Metabolism of cytokinin: Deribosylation of cytokinin ribonucleoside by adenosine nucleosidase from wheat germ cells. Plant Physiol. 1981, 68, 1020-1023. [CrossRef]

(C) 2020 by the authors. Licensee MDPI, Basel, Switzerland. This article is an open access article distributed under the terms and conditions of the Creative Commons Attribution (CC BY) license (http://creativecommons.org/licenses/by/4.0/). 